\title{
Students' attitudes, knowledge, and commitment to implementation of multicultural education in a teacher education program
}

\author{
Pei Jian Zhou \\ West Virginia University
}

Follow this and additional works at: https://researchrepository.wvu.edu/etd

\section{Recommended Citation}

Zhou, Pei Jian, "Students' attitudes, knowledge, and commitment to implementation of multicultural education in a teacher education program" (2002). Graduate Theses, Dissertations, and Problem Reports. 2452.

https://researchrepository.wvu.edu/etd/2452

This Dissertation is protected by copyright and/or related rights. It has been brought to you by the The Research Repository @ WVU with permission from the rights-holder(s). You are free to use this Dissertation in any way that is permitted by the copyright and related rights legislation that applies to your use. For other uses you must obtain permission from the rights-holder(s) directly, unless additional rights are indicated by a Creative Commons license in the record and/ or on the work itself. This Dissertation has been accepted for inclusion in WVU Graduate Theses, Dissertations, and Problem Reports collection by an authorized administrator of The Research Repository @ WVU.

For more information, please contact researchrepository@mail.wvu.edu. 


\title{
Students' Attitudes, Knowledge, and Commitment to Implementation of Multicultural Education in a Teacher Education Program
}

\author{
Pei Jian Zhou \\ Dissertation Submitted to the College of \\ Human Resources and Education at West Virginia University \\ in Partial Fulfillment of Requirements for the Degree of \\ Doctor of Education \\ in \\ Curriculum and Instruction \\ Ardeth Deay, Ph.D, Chair \\ Kenneth Murray, Ph.D \\ Perry Phillips, Ph.D \\ Ranjit Majumder, Ph.D \\ Samuel Stack, Ph.D \\ Jane Cardi, Ed.D
}

Department of Educational Theory and Practice

Morgantown, West Virginia

2002

Copyright 2002 Pei Jian Zhou 


\section{ABSTRACT \\ Students' Attitudes, Knowledge, and Commitment to Implementation of Multicultural Education in a Teacher Education Program \\ Pei Jian Zhou}

In recent years, there are more research studies in the field of teacher education. These research studies examine the effects of multicultural education initiatives on the change of students' attitudes and perspectives on multicultural education in teacher education programs. The results of these research studies have revealed that further studies are called for in this area of study, because the results of the previous studies are not always positive and clear. The purpose of this study is to see if there is any attitude change during the program, how the five-year teacher education program enhances the pre-service teacher education experience by examining diversity issues from various perspectives and how the program helps pre-service teachers to apply what they have learned from the courses to modify instruction appropriately.

This study uses a mixed method of both quantitative and qualitative research approaches to examine the three research questions. The quantitative data was collected by using the "Diversity Questionnaire". The qualitative data was obtained through the analysis of the responses from a set of "Cultural Diversity Essay Questions" and questions of three "Case Studies".

The results of T-Test for Diversity Questionnaire indicate that there is no much evidence showing the students' attitude change between Year 3 and Year 4 groups. The reason for this result might be that the one-year difference between the two groups is not sufficient or long enough to see the differences of attitude change. Two instruments -- the 
"Essay Questions" and "Case Studies" were used for measurement qualitatively to access what the students have learned from the diversity strand in the teacher education program and to answer the second and the third research questions. The data reveals that the multicultural/diversity perspectives the participants have learned from the courses really help them to understand their students' situations better. This study also suggests that the students have developed and formed their positive attitudes toward diversity with the progress of their teacher education program and their field experiences. The effectiveness of the "Teacher Education Diversity Strand", the implications for teacher education curriculum and teaching, and the implications for further study are discussed. 


\section{ACKNOWLEDGEMENTS}

I am deeply grateful to those who help me to make this dissertation possible. I wish to express my gratitude to the following people who provided great help and support from development of research instruments, data collection, to data analysis, including Robert A. Wiggins from Oakland University, Elizabeth Iglesias, Dara Shaw, Helen Huntley, Julie S. Vargas, Patricia A. Haught, Mary Haas, Larry Stead, Andrew Katayama, and Sara Steel from this University.

I wish to thank my chair Ardeth Deay for many hours reading the drafts of each chapter, for her continuous encouragement and patient instruction and for her kindness and help all these years. Her support and encouragement always give me strength and courage to do my job better and I'll never forget it.

I wish to thank the members of my committee, Kenneth Murray, Perry Phillips, Ranjit Majumder, Samual Stack, and Jane Cardi for their insightful suggestions, advice, their kindness and support.

I wish to thank my wife and my son who have been supporting and understanding me all these years. Their support and understanding give me courage to face challenges ahead of me and never give up in front of difficulties.

Finally, I wish to thank the faculty who taught me at West Virginia University. I believe that I received excellent training throughout the doctoral program from the remarkable faculty, including Ardeth Deay, Michael Reed, Samual Stack, Ron Iannone, Pat Obenauf, and John Wells. 


\section{TABLE OF CONTENTS}

LIST OF TABLES AND FIGURE.

vii

CHAPTER

PAGE

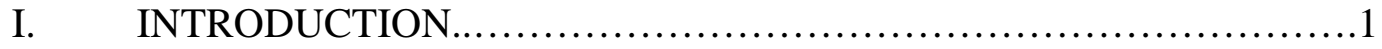

Rationale ........................................................

Statement of Problem ...............................................6

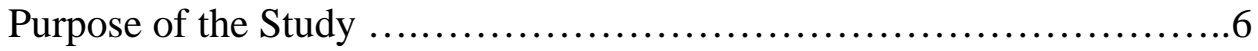

Research Questions..............................................

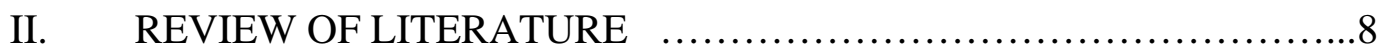

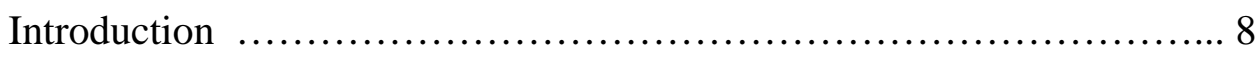

Conceptual History of Multicultural Education ....................... 8

Definition of Multicultural Education............................... 13

Research in Teacher Education ..................................... 17

Conclusion ................................................24

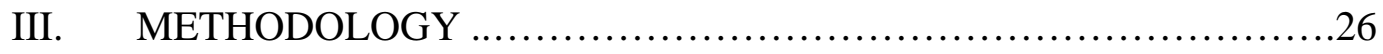

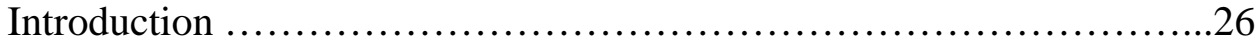

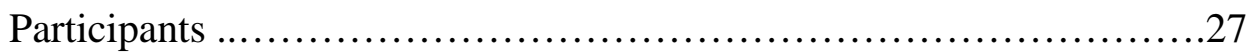

Measurement .................................................. 28

Procedures .................................................... 30

Research Design .............................................. 30

Data Analysis ............................................... 31

IV. DATA REPORT AND ANALYSIS .............................. 33

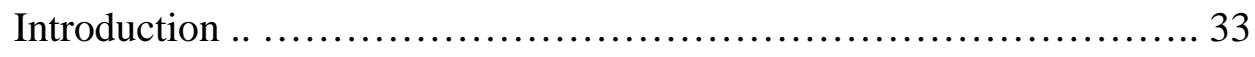

Diversity Questionnaire Data and Analysis ........................... 34

Diversity Essay Question Data Report and Analysis .................... 38

The Thematic Domains .......................................... 41

1. The Perspectives the Students have Learned......................41

2. Their Attitudes, Knowledge and Commitment ...................46

3. Their Knowledge and Experience ............................52

4. Their Commitment to Equity and Diversity .......................56

5. What They Need to Know More About ..........................57

6. The Situations in the Field ...................................64

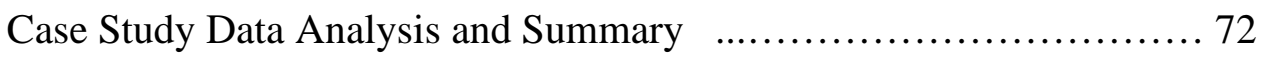

Summary of the Idea Units of the Case Studies (Year 4) ...............72

The Thematic Domains for Case Studies ............................. 74 
V. CONCLUSION AND DISCUSSION .............................. 84

Conclusions ...................................................... 84

Diversity Questionnaire....................................84

Diversity Essay Questions ................................85

Case Studies ............................................. 88

Discussion ....................................................90

Teacher Education Diversity Strand.......................... 90

Implications for Teacher Education Curriculum and Teaching....91

Implications for Further Study ............................93

REFFERENCES ............................................... 96

APPENDIX A: $\quad$ DIVERSITY QUESTIONNAIRE ..............103 APPENDIX B: $\quad$ CULTURAL DIVERSITY ESSAY QUESTIONS

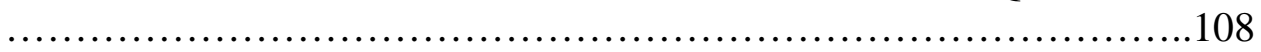

APPENDIX C: $\quad$ CASE STUDIES .............................109 


\section{LIST OF TABLES AND FIGURE}

TABLE 1. T-Test Result on Diversity Questionnaire ................................

TABLE 2. Univariate Analysis of Variance (Factorial ANOVA 2 x 3 design)............35

FIGURE 1. Profile Plots..................................................... 37

TABLE 3. Idea Units for Year 3 and Year 4 on Diversity Essay Questions..............38

TABLE 4. Case 1............................................................. 72

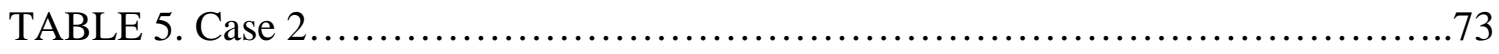

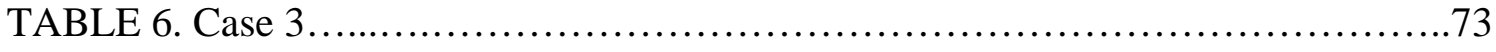




\section{CHAPTER I \\ INTRODUCTION}

\section{$\underline{\text { Rationale }}$}

Multicultural education is one of the most important issues within the ongoing educational debate in the United States. Student populations in the United States are becoming increasingly diverse. A growing number of American classrooms and schools contain a complex mix of races, cultures, languages, and religious affiliations (Banks 1994). According to National Center for Education Statistics in 1996, 31.5\% of students in American schools were minorities, and in city schools, 54\% were minorities (Wiggins \& Follo, 1999).

As a democratic nation of more than 200 years standing, the United States is built upon principles that are continuously being negotiated as to their application. Multicultural education in the United States originated in the 1960s in the wake of the civil rights movement as a correction to the long-standing de facto policy of assimilating minority groups into the "melting pot" of dominant American culture (Sobol, 1990). Multicultural education has captured almost daily headlines in recent years, as it has become an increasing contentious and politicized battleground. In the midst of such controversy, there has been little agreement on a precise conceptualization of multicultural education. Clearly, multicultural education, as practiced in the United States, takes many varied forms (Burnnet, 1994). During the past three decades, the focus of the debate over multicultural education can be traced back to issues of assimilation and pluralism. 
According to James A. Banks (1993a), the major goal of multicultural education is to restructure schools so that all students will acquire the knowledge, attitudes, and skills needed to function in an ethnically and racially diverse nation and world.

Multiculturalism is helping to develop more positive attitudes among students of different cultural backgrounds and it is hoped that it will eventually reshape the American identity in a positive way. On the other hand, Linda Chavez argues that multiculturalists confuse race and national origin with cultural attributes and wrongly dismiss the idea of one common American culture. She contends that most minorities and immigrants strive for assimilation into the mainstream culture; therefore, multiculturalism is not a grassroots movement but a political strategy for keeping the country culturally divided (Chavez, 1994). The assimilation theory argues that there is a dominant group (ingroup) culture in the society, and over time the incoming groups (outgroups) have to accept the mainstream way of life and discard their own ethnic social and cultural ties. The pluralism theory contends that, regardless of length of residence in the foreign countries, the incoming groups should retain their identities and resist the influence of naturalization. This debate is still going on today in the field of multicultural education. However, during the past three decades, educators have made great efforts to implement multicultural education in educational practices.

In his research, James A. Banks has identified five dimensions of multicultural education to help educators to implement and assess programs that respond to student diversity. Namely, 1) content integration, 2) knowledge construction, 3) prejudice reduction, 4) equitable pedagogy, and 5) empowering school culture and social structure dimensions (Banks 1994). 
Briefly, content integration describes the ways in which teachers use examples and content from a variety of cultures and groups to illustrate key concepts, principles, generalizations, and theories in their subject area or discipline.

The knowledge construction process consists of the methods, activities, and questions used by teachers to help students understand, investigate, and determine how implicit cultural assumptions, frames of reference, perspectives, and biases within a discipline influence the ways in which knowledge is constructed. When the knowledge construction process is implemented, teachers help students to understand how knowledge is created and how it is influenced by the racial, ethnic, and social-class positions of individuals and groups.

The prejudice reduction dimension of multicultural education relates to the characteristics of students' racial attitudes and strategies that teachers can use to help them develop more democratic values and attitudes. This research suggests that teachers in all subject areas need to take action to help students develop more democratic racial attitudes and values. It also suggests that interventions work best when children are young. As children grow older, it becomes increasingly difficult to modify their racial attitudes and beliefs.

Equity pedagogy exists when teachers modify their teaching in ways that will facilitate the academic achievement of students from diverse racial, ethnic, cultural, and gender groups. This research indicates that the academic achievement of students of color and low-income students can be increased when teaching strategies and activities build upon the cultural and linguistic strengths of students, and when teachers have cultural competency in the cultures of their students. 
An empowering school culture and social structure conceptualizes the school as a complex social system, whereas the other dimensions deal with particular aspects of a school or educational setting. This dimension conceptualizes the school as a social system that is larger than any of its constituent parts such as the curriculum, teaching materials, and teacher attitudes and perceptions. The systemic view of schools requires that in order to effectively reform schools, the entire system must be restructured, not just some of its parts. Although reform may begin with any one of the parts of a system (such as with the curriculum or with staff development), the other parts of the system (such as textbooks and the assessment program) must also be restructured in order to effectively implement school reform related to diversity (Banks, 1992).

The 1960s to the early 1990s was a period when multicultural theorists devoted much of their attention to preparing essays and writing books defining and describing multicultural education, and declaring and celebrating it as a field of scholarship (Grant $\&$ Tate 1995). Research studies on pre-service programs that focus on multicultural education are limited. It is important to note that research on multicultural issues in teacher education, in general, is sparse (Grant \& Tate 1995). Houston (1990), editor of the handbook of Research on Teacher Education, stated: "There has been notable recent progress, but the research basis for such important work as educating the nation's teachers is still extremely thin. Although the importance of research is being espoused, little progress is being made" (p. ix). The research studies available cluster into the following areas: university-based workshops, courses, and programs; field immersion with and without pre-service courses; culturally diverse placement; and cooperating teachers and supervisors (Grant \& Tate 1995). 
In the last decade, especially in recent years, more research studies are available in the field of teacher education. Searching ERIC database and Internet sources, revealed 16 research studies, which examine the effects of multicultural education initiatives on the change of students' attitudes and perspectives on multicultural education in teacher education programs. These research studies were conducted by Regan (1983), Wergin (1989), Moore and Reeves-Kazelskis (1992), Titus (1992), Reed (1993), Davis and Turner (1993), Sultana (1993), Sultana (1994), Gonzalez (1993), Chavez (1994), Chiang (1994), McCain-Reid (1994), Artiles (1995), Homan \& Person (1997), Winitzky \& Barlow (1998), and Wiggins \& Follo (1999). The results of these studies revealed noteworthy findings. Some of the studies indicate the significant attitude changes after multicultural education initiatives in some university educational programs. The research conducted by Winitzky \& Barlow, for example, investigated how pre-service teacher education program experiences and student life experiences related to positive changes in teacher candidates' attitudes toward student diversity. Results indicated that participants believed they had no understanding of teaching diverse students upon program entrance, but their attitudes shifted markedly by the end of the program. Most had made a firm commitment to several multicultural education practices. Shared personal characteristics of belief changes include an openness to learning and to new ideas; proactive behavior to learn about diversity; high empathy for minority students; and significant caring about social justice. Changers tended to seek out experiences with diverse cultures. They believed that a multiculturalism class they completed helped raise their awareness about diversity (Winitzky \& Barlow, 1998). However, the results of these research studies also have revealed that further studies are called for in the aspect of the assessment of 
students' attitudes, knowledge, and commitment to implementation of multicultural education in teacher education, because the results of the previous studies are not always positive and clear. They are varied depending on the research settings, participants, methodologies, and measurement.

\section{Statement of Problem}

The problem for this study is to analyze the impact of the teacher education diversity strand in a five-year teacher education program on participants' perceptions toward diverse student populations.

\section{Purpose of the Study}

Given the wide interest in theories and practices of multicultural education and the importance of the results, it is important to examine the development of students' knowledge, attitudes and commitment so as to improve the education programs for perspective teachers. Multicultural education has offered new perceptions and options in teaching students in a classroom of diversity. While the students in the teacher preparation program are learning the theory of multicultural education, it is necessary to understand how they are affected by the diversity strand that is integrated in the teacher preparation program. Therefore, the purpose of this study is to see how the five-year teacher education program enhances the pre-service teacher education experience by examining diversity issues from various perspectives and how the program helps preservice teachers to apply what they have learned from the courses to modify instruction appropriately. Therefore, for students whose majors are in education and who would be most likely to be teachers after graduation, it is important to know their perceptions and attitudes about multicultural education so as to guide them in their learning. At the same 
time, some perspectives on how to improve teaching and curriculum regarding to the integration of multicultural education theories and practices in teaching pre-service teachers may be revealed

\section{$\underline{\text { Research Questions }}$}

The specific questions of this study are:

1. What are the attitudes toward diversity among pre-service teachers at different points in the five-year teacher education program?

2. What have the pre-service teachers learned from the teacher education diversity strand?

3. How does the pre-service teachers' awareness of diversity help them to plan and implement multicultural education elements in their teaching? 


\section{CHAPTER II \\ REVIEW OF RELATED LITERATURE}

\section{Introduction}

Multicultural education, as a field of study, embraces a multitude of themes. The literature review for this study is organized into four sections to add clarity for the readers concerning how multicultural education emerged as field of study, what it is all about, and how it relates to my research topic. The first section addresses the conceptual history of multicultural education. The second section addresses the definitions of multicultural education from the scholars in this field. The third section addresses the research studies in multicultural pre-service teacher education, and focuses mainly on the assessment of students' attitudes, beliefs, knowledge, and commitment to implementation concerning diversity and multicultural education. The last section provides the researcher's conclusion of the findings concerning the literature review in order to clarify the necessity of this research effort.

\section{Conceptual History of Multicultural Education}

The philosophical precepts of multicultural education are most strongly connected to the progressive movement of educational research. Multicultural education as an educational philosophy and ideology was born out of the civil rights movements of the 1960s and the early 1970s. It was originally conceptualized as an educational effort to counter racism in schools. The civil rights movement provided the direct social impetus for multicultural education. It revived interest in studies of ethnic minority groups that aimed toward radical social change (Carmichael \& Hamilton, 1967). At the college level, 
the institution of black studies soon was followed by Chicano, Asian American, and Native American studies. Later, the idea single-group studies extended to women's studies, disability studies, and gay and lesbian studies. Although these studies differed by group, they commonly challenged the neutrality of knowledge and the centrality of white men in curriculum, and sought to develop a sense of group pride and to teach about discrimination against minority groups (Boyle, 1999).

Boyle, (1999) conducted a qualitative study to explore the historical trends in multicultural education. The primary sources of information were interviews with scholars who were central to founding the field such as James A. Banks, Carl Grant, Christine Bennett, Geneva Gay, Carlos Cortes, Donna Gollnick, Wilma Longstreet, and Christine Sleeter. Based on this research study, the conceptual history of multicultural education has gone through the following periods: 1) Quest for ethnic content, 2) Movement from multiethnic to multicultural education, 3) The move to greater inclusion, and 4) Searching for conceptual clarity.

The first generation of scholars in multicultural education came to the field from ethnic studies. James Banks called this time a quest for ethnic content. Banks, Gay, and Grant also were interested in strengthening educational access and achievement for children of color. Grant, however, held a broader view, he believed that he had always looked upon the field as multicultural. The reason is that it has always been larger than black and white issues and it needs to include other groups like women and those who are disabled (Boyle, 1999).

Many early scholars moved in an evolutionary fashion from ethnic to multiethnic to multicultural studies. Some, like Geneva Gay, barely paused at ethnic studies on the way 
to a more comparative multiethnic view. Others, like Carlos Cortes, questioned the extent to which multiethnic studies were conceptualized as something more than a collection of ethnic studies. Carl Grant and others, on the other hand, moved directly to the development of multicultural education (Boyle, 1999).

The publication of Banks' book Teaching Ethnic Studies: Concepts and Strategies in 1973 marked a new period of development of the concept of multicultural education. Cortes developed his own understanding of the concept and sought to find ways to compare ethnic group experiences. He used the idea of multiple perspectives to view history through a comparative lens. He developed a new frame of reference that criticized the east-west, Eurocentric focus for U.S. history. In an article in Educational Leadership, Cortes argued that US history developed from northwesterly slave trade south to north colonization and east-to-west immigration (Cortes, 1976). The article provided a novel way to view history from the perspectives of different ethnic groups (Boyle-Baise, 1999).

In 1976 Banks chaired the Task Force on Ethnic Studies Curriculum Guidelines for the National Council for the Social Studies. Gay and Cortes also served as members of this project. The task force used the term "multiethnic" rather than "multicultural" education in order to focus its concerns on race and ethnicity (Banks, 1992). Grant disagreed about the importance of several terms. He stated that sometimes the term "ethnicity" was used in titles of articles that were actually about multicultural education. Additionally, "ethnic studies," "multiethnic studies," and "multicultural education" were used interchangeably. As an example, Grant, Sleeter, and Boyle's monograph, The Public School and the challenge of Ethnic Pluralism, discussed multicultural education but offered meager treatment of ethnic pluralism (Grant, Sleeter, and Boyle1980). 
In the late 1970s, Christine Bennett developed a model for comprehensive multicultural education. She sought to help pre-service teachers connect with all their students. In her extensive literature search for information about race relations, multicultural education, and ethnic studies, she discovered that most research dealt with ethnic perspectives of history. She concluded that some of this literature confronted racism, but most of it did not. A small body of literature focused on cultural styles and institutional racism. She generated a comprehensive view of multicultural education that included four dimensions: movement toward educational equity, curricular reform, becoming an intercultural person, and combating prejudice and discrimination. The concept of cultural pluralism added another dimension to multicultural education (Boyle, 1999).

In 1978, Carl Grant furthered discussion about the nature of multicultural education. He argued against the term "multicultural education" and in favor of the phrase "an education that is multicultural (Grant, 1978)." To Grant, the first term modified education, whereas the second phrase suggested the entire transformation of schooling. Like Banks, Grant defined an education that is multicultural as all-encompassing. Faculty, curriculum, language, and instructional materials should reflect regard for cultural diversity. Regardless of the term used, by the late 1970s multicultural education was perceived as pluralistic, comprehensive, and transformative.

During the late 1970s and early 1980s, the thrust of civil rights advocacy expanded to include rights for women and people with disabling conditions. Following a path similar to that of early scholars, advocates for gender and disability rights challenged biased school policies, procedures, and curriculum content. Although gender and disability 
issues were distinct from racial and ethnic concerns, the confrontations with discriminatory school practices were similar. To support struggles against inequality, yet avoid the complications of multiple, separate group agendas, national associations, such as NCATE, addressed race, gender, and disability under the mantle of multicultural education. For some scholars, such as Christine Sleeter, the expanded discussion of educational rights motivated theoretical connections across race, gender, social class, and disability (Boyle, 1999).

By the latter 1980s, multicultural education meant different things to different people. In search of conceptual clarity, Sleeter and Grant reviewed the literature about multicultural education. They found five approaches operative within the field. They examined each approach and suggested limitations and strengths of each. They did not endorse any approach or try to delineate a common multicultural education. Rather they settled for vague common foundation: "the only common meaning is that it refers to changes in education that are supposed to benefit people of color (Sleeter \& Grant 1987)." Subsequently, Sleeter and Grant took a stronger stance. In Making Choices for Multicultural Education, they supported an approach called "education that is multicultural and social reconstructionist." This approach emphasized educational responsiveness to social/structural inequality color (Sleeter \& Grant 1994). Currently, the inclusion of gay and lesbian issues in multicultural education is debated. Banks recognized "absolutely no consensus" about this concern. For Banks, further clarification of the field was needed. Cortes agreed. He noted that the field "is not too big, but is so big that it makes it difficult to define a common core." The question raised by Gay in 1983 remained pertinent: Can you expand the boundaries of a field indefinitely and still 
protect its integrity? (Boyle, 1999).

\section{$\underline{\text { Definition of Multicultural Education }}$}

Specific definitions of multicultural education vary widely with respect to content selection, methodological focus, and referent group orientations. However, strong definitions can be grouped into several recurrent categories. The following are the major definitions of multicultural education defined by the influential scholars in this field.

Banks (1993b) identifies the major components when he explains that multicultural education is an idea, an educational reform movement, and a process whose major goal is to change the structure of educational institutions.

Garcia (1982), Grant (1977a, 1978) and L. Frazier (1977) state that multicultural education is a concept, a framework, a way of thinking, a philosophical viewpoint, a value orientation, and a set of criteria for making decisions that better serve the educational needs of culturally diverse student populations. As a concept, idea, or philosophy, multicultural education is a set of beliefs and explanations that recognizes and values the importance of ethnic and cultural diversity in shaping lifestyles, social experiences, personal identities, and educational opportunities of individuals, groups, and nations.

Parekh (1986) equates multicultural education with a refined version of liberal education, education for freedom, and celebration of the inherent plurality of the world. Bennett (1990), Banks (1990, 1991/92), Gay (1988), and Garcia (1982) proclaim that it is a crucial part of the democratic imperative for U.S. schools and society.

Grant (1977b) connects multicultural education to its own value traditions by defining it as a humanistic concept; establishes it as a condition of quality education for 
culturally pluralistic student populations; and suggests that it is based upon the principles of equality, human rights, social justice, and alternative life choices. The conception of multicultural education as an alternative way of thinking about how to provide quality education for diverse groups within the context of democratic ideas is further refined by Baptiste (1979), Bennett (1990), Banks (1990), Sleeter (1991), Garcia (1982), Gay (1988, 1990), and Nieto (1992).

Conceptions of multicultural education as a reform movement emphasize revising the structural, procedural, substantive, and valuative components of the educational enterprise to reflect the social, cultural, ethnic, racial, and linguistic pluralism present in the United States. They tend to be prescriptive in content and transactive and transformative in intent. These elements are implied in Baptiste's (1979) explanation of multicultural education as a "process of institutionalizing the philosophy of cultural pluralism within the educational system" (p. 172). The operative word here is institutionalizing," which requires systematic efforts and systematic change (Banks, 1992; Gollnick \& Chinn, 1990; Nieto, 1992; Sleeter, 1991).

Bennett (1990) extends this notion of systematic change by identifying some of the specific elements of a multicultural reform movement. According to her, it must be comprehensive in focus, governed by principles of equality and equity, and encompass (a) approaches to curricula that develop understanding of ethnic groups' cultures, histories, and contributions; (b) processes for students becoming multicultural in their attitudes, values, beliefs, and behaviors; and (c) action strategies for combating racism and other forms of oppressive practice. Similar prescriptions are offered by Banks (1977, 1992), who states that multicultural education involves modifications in the total school 
environment, including policies and politics; classroom instructional interactions, materials, and resources; extracurricular activities; formal and informal curricula; performance appraisal techniques; guidance and counseling; and institutional norms.

L. Frazier (1977), Gollnick and Chinn (1990), and Banks and Banks (1993) broaden the notion of multicultural education as comprehensive reform by extending the referent group parameters to include social class, gender, and disability, along with race and ethnicity. Sleeter and Grant (1988) did likewise, as well as including a strong argument for social reconstruction as the ultimate outcome in their definition of multicultural education. This goal is achieved by teaching political action skills to youths so they can coalesce their efforts to work for the elimination of oppression in society and bring about a more equitable distribution of resources and opportunities for all oppressed groups. Therefore, social transformation and personal empowerment are fundamental themes within and characteristic traits of theoretical concepts of multicultural education as an emancipatory pedagogical and social reform movement.

Increasingly, multicultural education is seen as a process instead of a product. As a process, it is a way of thinking, a decision-making style, and a way of behaving in educational settings that is pervasive and ongoing (Banks, 1993c). It requires long-term investments of time and resources, and carefully planned and monitored actions. It evokes images similar to Beauchamp's conception of curriculum as a decision-making or "engineering" system for the creation, implementation, and evaluation of instructional plans. Grant (1978) captures the essence of this conception when he explains why he prefers to use education that is multicultural to identify the enterprise instead of multicultural education. Rather than a specific, discrete education program (such as 
social studies, bilingual, or science education), he sees multicultural education as a different approach to the entire educational enterprise in all its forms and functions.

Suzuki (1984) describes multicultural education as an interdisciplinary instructional program that "provides multiple learning environments matching the academic, social, and linguistic needs of students (p. 305). This program also has multiple purposes, among which are: (a) develop basic academic skills for students from different race, sex, ethnic, and social-class backgrounds; (b) teach students to respect and appreciate their own and other cultural groups; (c) overcome ethnocentric and prejudicial attitudes; (d) understand the sociohistorical, economic, and psychological factors that have produced contemporary ethnic alienation and inequality; (e) foster ability to analyze critically and make intelligent decisions about real-life ethnic, racial, and cultural problems; and (f) help students conceptualize and aspire toward a vision of a more humane, just, free, and equal society, and acquire the knowledge and skills necessary to achieve it (Suzuki, 1979).

Sizemore (1981) uses "process" somewhat analogously to "program" in her conception of multicultural education as "the process of acquiring knowledge and information about the efforts of different groups against adverse agencies and conditions for control of their destinies through the study of the artifacts and substances which emanated therefrom"(pp. $4-5)$.

Probably the most inclusive and eclectic definition of multicultural education is one by Nieto (1992). While many other scholars use multiple elements such as content, process, ideology, and reform in their conceptions of multicultural education, Nieto's is by far the most comprehensive. She places multicultural education in a sociopolitical context, and 
incorporates substantive and procedural components, outcome expectations, and some interpretive comments. The result is a synergistic composite that includes some features of most of the various types of definition discussed above. Nieto states that multicultural education is a process of comprehensive school reform and basic education for all students. It challenges and rejects racism and other forms of discrimination in schools and society and accepts and affirms the pluralism (such as ethnic, racial, linguistic, religious, economic, and gender, among others) that students, their communities, and teachers represent. Multicultural education permeates the curriculum and instructional strategies used in schools, as well as the interactions among teachers, students and parents, and the very way that schools conceptualize the nature of teaching and learning. Because it uses critical pedagogy as its underlying philosophy and focuses on knowledge, reflection, and action (praxis) as the basis for social change, multicultural education furthers the democratic principles of social justice (Nieto, 1992).

\section{$\underline{\text { Research in Teacher Education }}$}

Teacher educators currently face the challenge of preparing a mostly white teaching force to teach an increasingly diverse student population (Webb-Johnson \& Artiles 1998). A review of the research indicated that teacher education tended to focus on three issues: The effectiveness of a multicultural education course or methodology of instruction on teacher knowledge, teacher attitude, and teacher behavior (Regan, 1983; Titus, 1992; Gonzalez, 1993; Moore, \& Reeves, 1992); The effects or impact of multicultural education course or of teacher preparation program components on pre-service teachers' beliefs, attitudes, knowledge, and perceptions (Davis \& Turner, 1993; Chavez, \& others, 1994; Chiang, 1994; McCain, 1994; Artiles, \& others, 1995; Homan \& Person, 1997; 
Winitzky \& Barlow, 1998; Wiggins \& Follo, 1999); and pre-service teachers’ beliefs, attitudes, knowledge, and perceptions about diversity (e.g. how do they value diversity/multicultural education) (Wergin, 1989; Reed, 1993; Sultana, 1993; Sultana, 1994).

Research studies on the effectiveness of a multicultural course or methodology of instruction on teacher knowledge, teacher attitude, and teacher behavior showed very interesting findings. In 1983, Stephen D. Regan conducted a study to investigate the effectiveness of the human relations' course on teacher knowledge, teacher attitude, and teacher behavior in a mandated multicultural education program in Iowa. The participants were randomly selected students one year after they completed the course. Two instruments were used in the study: a Course Evaluation Form and a Questionnaire. The results indicated that no significant gains appeared for either attitude or knowledge on the effectiveness of the human relations' course on teacher knowledge, teacher attitude, and teacher behavior. Faulty administration, inadequate guidelines, and a lack of real support for the program from various official levels of education may explain the lack of significant gains and the image of the mandated program as a boondoggle (Regan, 1983).

In 1992, Titus conducted a pilot study to assess secondary social studies teachers' attitudes concerning multiculturalism, to examine what the teachers are doing to infuse multiculturalism into the curriculum, to determine the constraints on their implementation, and to explore teacher attitudes concerning pre-service and in-service multicultural teacher preparation efforts. Twenty-six social studies teachers in three high schools and two junior high schools took part in the study. Data was collected through a 
42-item questionnaire. Results showed that most secondary social studies teachers had positive attitudes toward multicultural education and its infusion into the curriculum. However, the effectiveness of preservice multicultural instruction was rated as low by the majority of teachers (Titus, 1992).

Gonzalez found in a descriptive survey study on the academic and personal characteristics of inservice teachers who were taking a graduate course in multicultural education issues that reflective teaching could be used as an effective ethnographic research tool, as well as an effective psycho pedagogical strategy for multicultural education. Fifty-five students participated in this study with the age range varied from 20 to 55 years old. The results of the study suggested that higher levels of academic knowledge occur due to an increase in awareness levels of attitudinal belief systems gained through self-reflection and that teachers became more sensitive and aware of their influence on assuring educational success for culturally and linguistically diverse children (Gonzales, 1993).

Moore and Reeves conducted a study in 1992 to determine whether formal instruction in multicultural education would produce changes in preservice teachers' beliefs about diversity. Thirty-one preservice teachers enrolled in 2 sections of a practicum course in early childhood education participated in the study. The participants responded to the Survey of Multicultural Education Concepts (SMEC) before and after the course as preand post-tests. The results indicated that carefully planned and implemented formal instruction might be used to change pre-service teachers' beliefs about cultural diversity (Moore \& Reeves, 1992). 
Multiple research studies on the effects or impact of multicultural education course or of teacher preparation program components on pre-service teachers' beliefs, attitudes, knowledge, and perceptions revealed a wealth of findings. Davis and Turner used the Cultural Diversity Awareness Inventory to measure the cultural sensitivity of the elementary pre-service teachers. They found in their study that elementary education majors exhibited cultural sensitivity in multicultural education topics but found no statistically significant differences based on race, participation in a multicultural education course, or prior high school attendance at a private or public school. They concluded that teacher education programs appear to be preparing preservice teachers to be culturally sensitive and separate multicultural courses added to the curriculum may not be needed (Davis \& Turner, 1993).

Chavez, and others used newspaper articles from local paper as dilemmas to assess students' ideas, beliefs, and attitude about multicultural issues, and to determine how the multicultural education course may affect the undergraduate pre-service teachers' view of the world. Sixty-five students participated in the study. The data analysis indicated that a majority of students entered the course with a linear perspective of the world; that their attitudes and beliefs largely reflected the racial status quo; and for the most part, that the course had little effect on students' developing perspectives. They concluded that to construct more socially and culturally sensitive perceptions, educational strategies are needed to confront three knowledge domains: the personal, the historical, and the ideological and cultural (Chavez et al., 1994).

Some study findings showed that positive changes in attitudes did begin to occur after the multicultural education course. McCain conducted a pilot study to determine the 
impact that two models of instruction had on students' learning. Subjects were 16 white females and 4 white males, with an African American female professor as the principal investigator. The participants were asked to keep journals, to prepare a paper on their philosophies of education, to critique their journals, to have an interview with the professor, and to complete a teaching demonstration and its evaluation. Positive changes in attitudes did begin to occur and the students exhibited distinct patterns of conceptual change after the course (McCain, 1994).

Chiang, Linda conducted a study in 1994 to examine the attitude of prospective teachers toward social diversity. The participants were from selected teacher education programs at two different universities. The group of prospective teachers from one university received instruction in multicultural education, and the other group did not. A questionnaire was used as the instrument for pre- and post-tests. One hundred thirty-four pre- post responses were collected for comparison. Findings of this study indicated that at the beginning of the participants' professional semester there was no significant difference between the two groups. At the end of the first professional semester there was a significant difference between the two groups. The participants who had received instruction in multicultural education reported more positive attitudes toward social diversity (Chiang, 1994).

Artiles and others conducted a study in 1995 to examine the impact of multicultural education courses on preservice teachers' pedagogical knowledge and beliefs about culturally diverse learners. Twenty pre-service teachers participated in the study. One part of the data were collected using concept mapping and a survey to assess the preservice teachers' beliefs and the other part of the data were collected using case studies 
based on in-depth interviews augmenting the existing data of two individuals who had participated in the first part of the study. Results indicated that participants in the first part of the study showed distinct patterns of conceptual change after the course, and the two individuals pursued distinct pathways in their changing conceptualizations of good teaching for diverse students though the two participants shared some similarities. (Artiles et al., 1995)

Winitzky \& Barlow conducted a study in 1998 to investigate how preservice teacher education program experiences and student life experiences related to positive changes in teacher candidates' attitudes toward student diversity. Five preservice teachers completed interviews during their final term in the program. Results indicated that participants believed they had no understanding of teaching diverse students upon program entrance, but their attitudes shifted markedly by the end of the program (Winitzky \& Barlow, 1998).

Homan and Person conducted a study to examine the multicultural perceptions and attitudinal shifts during student teaching of selected social studies student teachers. The results showed that five of the six student teachers did not demonstrate the knowledge and skills deemed necessary according to the literature to provide the opportunity for the successful academic performance of culturally diverse students, and four of the six had positive attitudes toward culturally diverse students, but only one had the knowledge, skills, and attitudes necessary to be successful in teaching culturally diverse students. Most of the student teachers in this study did not experience cognitive dissonance with culturally diverse students in the classroom and did not change their attitudes (Homan \& Person, 1997). 
Wiggins \& Follo conducted a study in 1999 to investigate the preparation and commitment of pre-service teachers to teach in culturally diverse settings. They raised questions about whether the teacher preparation programs adequately develop the abilities and the desire to teach in these settings. The participants were undergraduates enrolled in an elementary education program. Out of the total enrollment of 123 students in six classes, they had 90 paired responses from pre- and post-semester diversity questionnaires. They used the Statistical Package for the Social Sciences (SPSS) to analyze the data. Results indicated that students' experiences with multicultural settings occur through university courses and field experiences. These experiences appear to provide a knowledge base for successful teaching, but their attitudes or beliefs about teaching in such settings were not adequately affected (Wiggins \& Follo, 1999).

Studies to assess pre-service teachers' beliefs, attitudes, knowledge, and perceptions about diversity (e.g., how do they value diversity/multicultural education) also showed noteworthy findings. Wergin conducted a study in 1989 to assess freshmen attitudes in the areas of interest in cultural diversity, racism, ethnocentrism, and cross-cultural beliefs and values. The 81-item survey was given to 234 students at Virginia Commonwealth University. The results of the survey indicated that most freshmen participating the study express an interest in learning more about other cultures and they may be more comfortable dealing with issues of diversity in the abstract than in the concrete, and discussions of attitudes and beliefs are likely to arouse defensiveness (Wergin, 1989).

Reed conducted a study using pre-post surveys administered to preservice teachers at the beginning and conclusion of a course in multicultural education to determine their attitudes and perceptions. Thirteen preservice teachers participated in the study. Reed's 
study indicated that a multicultural project does not change deep-seated, personal feelings about minority groups (Reed, 1993).

Sultana conducted a study in 1993 to investigate on the level of attainment, the degree of sophistication, and the extent to which pre-service teachers are aware of, understand, appreciate, respect, and value multicultural education. 115 student teachers participated in the study and were asked to write a comprehensive definition of multicultural education. Results indicated that an adequate level of awareness existed, but this level of awareness is not sufficient to prepare pre-service teachers to function effectively (Sultana, 1993)

In another study, Sultana conducted a survey among 143 college students majoring in education and enrolled in an introductory education course to determine their understanding of and knowledge about multicultural education and to discern the extent to which these students appreciated and valued multicultural education. Results indicated that multicultural education was addressed in the subjects' high school curriculum, only to a limited degree. 11 percent of the subjects did not know anything about multicultural education. 55 percent were aware of cultural differences. Another 4.2 percent had some understanding of multicultural education. Six subjects had benefited from their multicultural education to a degree where they accepted, respected, and valued it (Sultana, 1994).

\section{$\underline{\text { Conclusion }}$}

Multicultural education, as a field of study, has gone through a series of stages of development and expanded its content on the way. A wealth of studies have been done to define and clarify its goals and objectives through the past few decades. Therefore, 
multicultural education has completed its task to establish itself as a field of scholarship.

Research studies have shifted their focus to the practice of integrating multicultural education into various fields of study in education. 


\section{CHAPTER III}

\section{METHODOLOGY}

\section{$\underline{\text { Introduction }}$}

This study focuses on the impact of the teacher education diversity strand on attitude changes, knowledge, and commitment for students in the teacher education program in the College of Human Resources and Education at a university located in the Mid-Atlantic region. This teacher preparation program is a five-year, dual degree program that leads to a bachelor's degree in a content specialization and a master's degree in education. According to a report, A New Vision for Teacher Education at West Virginia University ("New Vision") and Teacher Education Diversity Strand (TEDS) released by the Center for the Renewal of Professional Preparation and Practice (CRPPP) in 1994, the diversity strand is integrated throughout the program. During the program, students have opportunities to become aware of the importance of diversity and multicultural education issues. The students will become aware of opportunities to work with children of special needs and cultural diverse populations. They will participate in activities to help them understand issues of diversity such as participating in panel discussions, small group discussions and reflect on their experiences through writing. Students will study diversity in detail looking at social class, ethnicity, race, gender and special needs. Students will explore the issue of diversity through readings, presentations, film, video, and guest speakers (CRPPP, 1994 \& TEDS, 1994). 
From the literature review of the current research studies, the researcher has some findings that will guide this study. First of all, it is obvious that to assess teacher or preservice teacher attitudes, knowledge, and perceptions about diversity has become a trend in teacher education research. By saying this, the researcher means the fact that more research studies on this topic area have appeared since 1993. Secondly, further study is obviously called for in this area of teacher education for the reason that the results of the current studies are conflicting. They are various depending on the research settings, participants, methodologies, and measurement. Thirdly, the methodologies and instrument in these studies vary. Lastly, all the studies either used quantitative or qualitative research method, and no study used the mixed methods. Therefore, research with mixed methods may be a better option to interpret research results and look deeper into the implications of research studies.

Therefore, a mixed method of both quantitative and qualitative research approaches was used in this study to examine the three research questions. The quantitative data was collected by using the "Diversity Questionnaire" (See Appendix A). The qualitative data was obtained through the analysis of the responses from a set of "Essay Questions" (See Appendix B) and questions of three "Case Studies" (See Appendix C), and the data was used as supporting evidence to the results of the Diversity Questionnaire.

\section{Participants}

To determine the impact of the diversity strand in the teacher education program on student attitudes and perspectives, two groups (Year $3 \&$ Year 4) of 174 students participated in this study. Year 3 group was the students enrolled in EDUC 101. They were in their first semester of the third year in the program, and they had just finished 
their volunteer experience prior to acceptance into the program. Year 3 group was composed of 103 students with 12 males, 66 females, and 25 N/R (no response). Year 4 group was the students enrolled in EDUC 200: Instructional Design and Evaluation and EDUC 210: Practicum III. They were in the fourth year of the program, and they had been tutors in the previous year. Year 4 group was composed of 71 students with 9 males, 43 females, and $19 \mathrm{~N} / \mathrm{R}$ (on response).

\section{$\underline{\text { Measurement }}$}

The instruments used for measurement in this study were the "Diversity Questionnaire", "Essay Questions" and "Case Studies". The "Diversity Questionnaire" was developed by Dr. Eric Follo and Dr. Bob Wiggins at Oakland University in 1999. The instrument has proved very reliable. The reliability coefficients for the three categories of statements were $0.7728,0.6801$, and 0.8764 respectively (Cronbach Alphas) (Wiggins and Follo, 1999). This Diversity Questionnaire consists of 40 items, 5 items are about general information, and 35 items are statements about multicultural issues, which are composed of three categories, with a 1-5-response range for each statement to measure different attitudes toward diversity. Among the 35 statements, 11 statements address the category of factors that foster readiness for teaching in culturally diverse settings; 9 statements address the category of factors that constrain readiness for teaching in culturally diverse settings; and 15 statements address the category of factors related to experiences relative to multicultural education. Factors that foster readiness refer primarily to knowledge and skills, the pedagogical issues of lesson planning and instructional design. Factors that constrain readiness refer to awareness of cultural differences and issues of personal attitude. Factors related to experiences refer to 
students' exposure to multicultural communities, multicultural work experiences, or individuals from other cultures. In this study, the change of attitudes toward multicultural education was measured by using this instrument. This instrument is a valid measure for multicultural education because it has been proved reliable in Wiggins \& Follo's study. Given the content of the courses (the treatment), the students' attitudes will be affected by the issues, theories and their new perceptions of multicultural education after four years study in the teacher education program with the diversity strand integrated in the courses they have taken. The consistency of the test items for the two groups ensured the validity and the reliability of this instrument.

The "Essay Questions" and "Case Studies" were used as instruments to measure qualitatively for what the students have learned from the teacher education diversity strand and how the students' awareness of diversity help them to plan and implement multicultural education elements in their teaching. The development of the essay questions and the questions for three cases had gone through a few steps in order to make sure that the questions would serve the purpose of this study. The first draft of the essay questions consisted of twelve questions written by the researcher and then reduced to six questions with the advisor's input for the second draft. These six essay questions were brought to an expert discussion panel, which was composed of five people: the researcher, the researcher's academic program advisor, the coordinator of multicultural/diversity initiatives from College of Human Resources \& Education, and other two faculty members from the Diversity Task Force. The essay questions were carefully studied and discussed in accordance with the research questions of this study. With the supervision of the experts, three questions were selected and revised for the 
final version of the instrument. As for case studies, the researcher selected six case studies from “A Casebook for Exploring Diversity in K-12 Classrooms” by George L. Redman (George, 1999), and developed the reflection questions for each case. Three cases were selected and discussed at the expert discussion panel and the reflection questions were further revised for the final version.

\section{Procedures}

The data collection for this study was completed during the Fall Semester of the 2000 2001 academic year. The "Diversity Questionnaire" was conducted during the first class meetings for EDUC 101 - Learning; and EDUC 200 - Instructional Design \& Evaluation;

The Diversity Questionnaire data was collected by the instructors of each section at their first meeting. After a brief introduction to the study and the instrument, students were given the questionnaire material to complete within 20 to 30 minutes and they were collected when the students had completed.

The qualitative data were collected during the second and the third weeks of the fall semester, which include students' responses in writing to the essay questions and three case studies. The essay questions were administered in EDUC 101 - Learning, EDUC 200 - Instructional Design \& Evaluation respectively.

The case studies were administered in EDUC 210: Practicum III. Then, the responses were coded into categories of idea units and domains to determine what they have learned from the diversity strand and how they would implement them in their teaching practice.

\section{$\underline{\text { Research Design }}$}

The participants of this study were not randomly selected. They were students in a five-year teacher education program and enrolled in the courses: EDUC101, EDUC 200, 
and EDUC 212. This sample was stable through the whole semester. One of the independent variables of this study was the instructional context. The courses the two groups were taking had some focuses on the theory, practice and issues of diversity. The essay questions and case studies were the more specific independent variable for this study. The essay questions and case studies were used to assess the students' perceptions about diversity and multicultural education issues that they had learned in the courses. Another independent variable was the Diversity Questionnaire. As it is mentioned before, this questionnaire was conducted at the beginning of the fall semester for the two groups. Therefore, a mixed method of multiple assessments was used in this study.

\section{Data Analysis}

The differences of the two groups between the responses to the Diversity Questionnaire were compared and examined to see what changes had occurred concerning student attitudes and perceptions as a result of the progress in the teacher education program. The statistical package SPSS was used and a $t$ test was run on the mean values to determine the statistical significance of changes in the responses between the two groups. Univariate Analysis of Variance was run to determine if there are any effects or relationship between groups.

The written responses collected from the essay questions among the two groups and case studies in Year 4 group were coded and examined to determine the differences. To be more specific, the researcher subdivided them into individual idea units. Using these idea units, the researcher organized them into thematic groupings of the data, which were further analyzed. Therefore, several general conceptually distinct domains were emerged from the analysis of these data. The method of data analysis using idea units and thematic 
domains was adopted from a study " Perceptions of a Hypermedia Environment" (Min Liu, David J. Ayersman and W. Michael Reed 1995). In order to test the inter-rater reliability of the qualitative data, the researcher invited two faculty members from another college with experience working with diversity issues to review the raw data of the essay questions and case studies and list all the idea units they thought were important. Then, the researcher compared their results with his own and came to the conclusion that the agreement among the three people was above $90 \%$. Therefore, the analysis of the qualitative data had a strong inter-rater reliability.

The results of all the data analysis clearly answered the three research questions: 1) what are the attitudes toward diversity among students at different points in the five-year teacher education program? 2) What have the students learned from the teacher education diversity strand? 3) How does the students' awareness of diversity help them to plan and implement multicultural education elements in their teaching? 


\section{CHAPTER IV}

\section{DATA REPORT AND ANALYSIS}

\section{$\underline{\text { Introduction }}$}

Chapter IV contains the findings from the data collected from Diversity

Questionnaire, the written responses collected from the Diversity Essay Questions among the two groups --- Year 3 and Year 4, and the written responses collected from Year 4 group on Case Studies. The first section addresses the data which respond to the research question relating to student attitudes and perceptions as a result of the progress in the teacher education program: 1) "What are the attitudes toward diversity among students at different points in the five-year teacher education program?" The t-test results on the mean values are reported to show if there is any statistical significance of changes in the responses between the two groups and the effects or relationship among the three question categories by using Statistical Package for the Social Sciences (SPSS).

The second section addresses the data analysis of the Diversity Essay Questions that respond the research question relating to students' knowledge, experience, attitudes, and commitment. The data analysis of this section would answer the second research question: 2)"What have the students learned from the teacher education diversity strand?"

The third section addresses the data analysis of the Case Studies that would respond to the third research question: 3) "How does the students' awareness of diversity help them to plan and implement multicultural education elements in their teaching?" The summary tables of the idea units show the thematic groupings of the data, and it is followed by the 
dominant themes emerging from the data analysis of these idea units.

\section{Diversity Questionnaire Data Analysis}

In order to know from the Diversity Questionnaire data what changes had occurred as a result of one year's course work. A $t$ test was run on the mean values to determine the statistical significance of the changes. Table 1 below shows the results of the $t$ test by using the Statistical Package for the Social Sciences (SPSS).

Table 1: T-Test Result on Diversity Questionnaire for Year 3 \& Year 4 Group Statistics

\begin{tabular}{|cc|c|c|c|c|}
\hline & groups & $\mathrm{N}$ & Mean & $\begin{array}{c}\text { Std. } \\
\text { Deviation }\end{array}$ & $\begin{array}{c}\text { Std. Error } \\
\text { Mean }\end{array}$ \\
\hline attitude score mean & year 3 & 103 & 3.0835 & .2240 & $2.207 \mathrm{E}-02$ \\
& year 4 & 71 & 3.1475 & .2939 & $3.488 \mathrm{E}-02$ \\
\hline
\end{tabular}

Independent Samples Test

\begin{tabular}{|c|c|c|}
\hline \multirow{2}{*}{ attitude score mean } & \multicolumn{2}{|c|}{$\begin{array}{c}\text { Levene's Test for } \\
\text { Equality of Variances }\end{array}$} \\
\hline $\begin{array}{c}\text { Equal variances } \\
\text { assumed } \\
\text { Equal variances } \\
\text { not assumed }\end{array}$ & $\mathrm{F}$ & Sig. \\
\cline { 2 - 3 } & 4.760 & .030 \\
\hline
\end{tabular}

\begin{tabular}{|c|c|c|c|c|c|}
\hline & \multicolumn{4}{|c|}{ t-test for Equality of Means } \\
\hline & & $\mathrm{t}$ & $\mathrm{df}$ & $\begin{array}{c}\text { Sig. } \\
\text { (2-tailed) }\end{array}$ & $\begin{array}{c}\text { Mean } \\
\text { Difference }\end{array}$ \\
\hline attitude score mean & $\begin{array}{l}\text { Equal variances } \\
\text { assumed }\end{array}$ & -1.628 & 172 & .105 & $-6.3970 \mathrm{E}-02$ \\
\hline & $\begin{array}{l}\text { Equal variances } \\
\text { not assumed }\end{array}$ & -1.550 & 123.667 & .124 & $-6.3970 \mathrm{E}-02$ \\
\hline
\end{tabular}

\begin{tabular}{|c|c|c|c|c|}
\hline & \multicolumn{3}{|c|}{ t-test for Equality of Means } \\
\hline & & \multirow[b]{2}{*}{$\begin{array}{l}\text { Std. Error } \\
\text { Difference }\end{array}$} & \multicolumn{2}{|c|}{$\begin{array}{c}95 \% \text { Confidence Interval } \\
\text { of the Difference }\end{array}$} \\
\hline & & & Lower & Upper \\
\hline \multirow{2}{*}{\multicolumn{2}{|c|}{$\begin{array}{cc}\text { attitude score mean } & \text { Equal variances } \\
& \text { assumed } \\
& \text { Equal variances } \\
& \text { not assumed } \\
\end{array}$}} & $3.930 \mathrm{E}-02$ & -.1415 & $1.361 \mathrm{E}-02$ \\
\hline & & $4.128 \mathrm{E}-02$ & -.1457 & $1.774 \mathrm{E}-02$ \\
\hline
\end{tabular}


The t-test results of the SPSS output above show that in the t-test for Equality of Means, $\mathrm{P}$ value $=.105$. Therefore, there was no significance difference between the means of the year 3 and year 4 groups in the respect of attitude changes. That is to say that no significant differences between year 3 and year 4 groups had occurred as a result of one year's course work so far as attitude change was concerned.

In order to test the effects or relationship among the three categories of statements and to see if there were any differences within each group and between the two groups. A Univariate Analysis of Variance was run using SPSS package for the tests of betweensubjects effects. Table 2 shows the results of the analysis.

Table 2: Univariate Analysis of Variance (Factorial ANOVA 2 x 3 design)

Between-Subjects Factors

\begin{tabular}{|ll|l|r|}
\hline & & $\begin{array}{c}\text { Value } \\
\text { Label }\end{array}$ & $\mathrm{N}$ \\
\hline categories & 1 & cat 1 & 22 \\
of & 2 & cat 2 & 18 \\
questions & 3 & cat 3 & 30 \\
groups & 1 & year 3 & 35 \\
& 2 & year 4 & 35 \\
\hline
\end{tabular}

Descriptive Statistics

Dependent Variable: mean scores for year 3\&4

\begin{tabular}{|l|r|r|r|r|}
\hline \multicolumn{1}{|c|}{ categories of statements } & groups & Mean & $\begin{array}{c}\text { Std. } \\
\text { Deviation }\end{array}$ & $\mathrm{N}$ \\
\hline cat 1 & year 3 & 3.5700 & .4512 & 11 \\
Factors that foster the & year 4 & 3.6155 & .4509 & 11 \\
readiness & Total & 3.5927 & .4407 & 22 \\
& & & & .4892 \\
cat 2 & year 3 & 2.4900 & .5461 & 9 \\
Factors that constrain the & year 4 & 2.3878 & .5057 & 18 \\
readiness & Total & 2.4389 & & \\
& & & .6695 & 15 \\
\hline cat 3 & year 3 & 3.3120 & .5607 & 15 \\
Factors that related to & year 4 & 3.4893 & .6134 & 30 \\
experiences & Total & 3.4007 & & 9 \\
\hline
\end{tabular}




\begin{tabular}{|l|r|r|r|r|}
\hline Total & year 3 & 3.1817 & .6955 & 35 \\
& year 4 & 3.2457 & .7243 & 35 \\
& Total & 3.2137 & .7056 & 70 \\
\hline
\end{tabular}

\section{Tests of Between-Subjects Effects}

Dependent Variable: mean scores for year 3\&4

\begin{tabular}{|c|c|c|c|c|c|}
\hline Source & $\begin{array}{l}\text { Type III } \\
\text { Sum of } \\
\text { Squares }\end{array}$ & $\mathrm{df}$ & $\begin{array}{l}\text { Mean } \\
\text { Square }\end{array}$ & $\mathrm{F}$ & Sig. \\
\hline Corrected Model & $15.309 *$ & 5 & 3.062 & 10.289 & .000 \\
\hline Intercept & 662.243 & 1 & 662.243 & 2225.399 & .000 \\
\hline CATEGORY & 15.015 & 2 & 7.508 & 25.229 & .000 \\
\hline GROUPS & $2.705 \mathrm{E}-02$ & 1 & $2.70 \mathrm{E}-02$ & .091 & .764 \\
\hline CATEGORY \& & & & & & \\
\hline GROUPS & .223 & 2 & .111 & .374 & .690 \\
\hline Error & 19.045 & 64 & .298 & & \\
\hline Total & 757.312 & 70 & & & \\
\hline Corrected Total & 34.355 & 69 & & & \\
\hline
\end{tabular}

$* \mathrm{R}$ Squared $=.446$ (Adjusted R Squared $=.402$ )

From Table 2 above we know two things. Firstly, the main effect of groups is not significant for its $\mathrm{P}$ value is .764. Secondly, there is no interaction between category and groups for its $\mathrm{P}$ value is .690 which is larger than .05 . That is to say that there is no significant difference between Year 3 and Year 4 groups on the three categories of statements. And there is no interaction between the two groups on any category of statements.

The researcher accessed the attitudes of Year 3 and Year 4 groups towards diversity by looking at the responses to the diversity questionnaire. Year 3 and Year 4 groups got total mean values of $3.59,2.44$, and 3.21 respectively on the three categories of statements. Apparently, the second category of questions got a lower mean value on a 1-5 scale with 1 indicating "disagree strongly" and 5 indicating "agree strongly". But in fact the lower mean value (on the negative side of the scale) just indicated the positive attitude towards diversity issues because most of the statements in this category were 
more on the negative side. In order to make this point clearer, the researcher reversed those mean values of the statements in category 2 . Figure 1 shows the relationship between category of statements and the groups with the reversed mean values for some of the statements in category 2 . It shows that the participants of this study have got a positive personal attitude towards diversity and a better awareness of cultural differences because their mean values for each category of statements are higher than scale 3 . Figure 1 also shows that there are no interactions between Year 3 and Year 4 groups on any category of statements.

\section{FIGURE 1}

\section{Profile Plots}

Estimated Marginal Means of mean scores for year $3 \& 4$

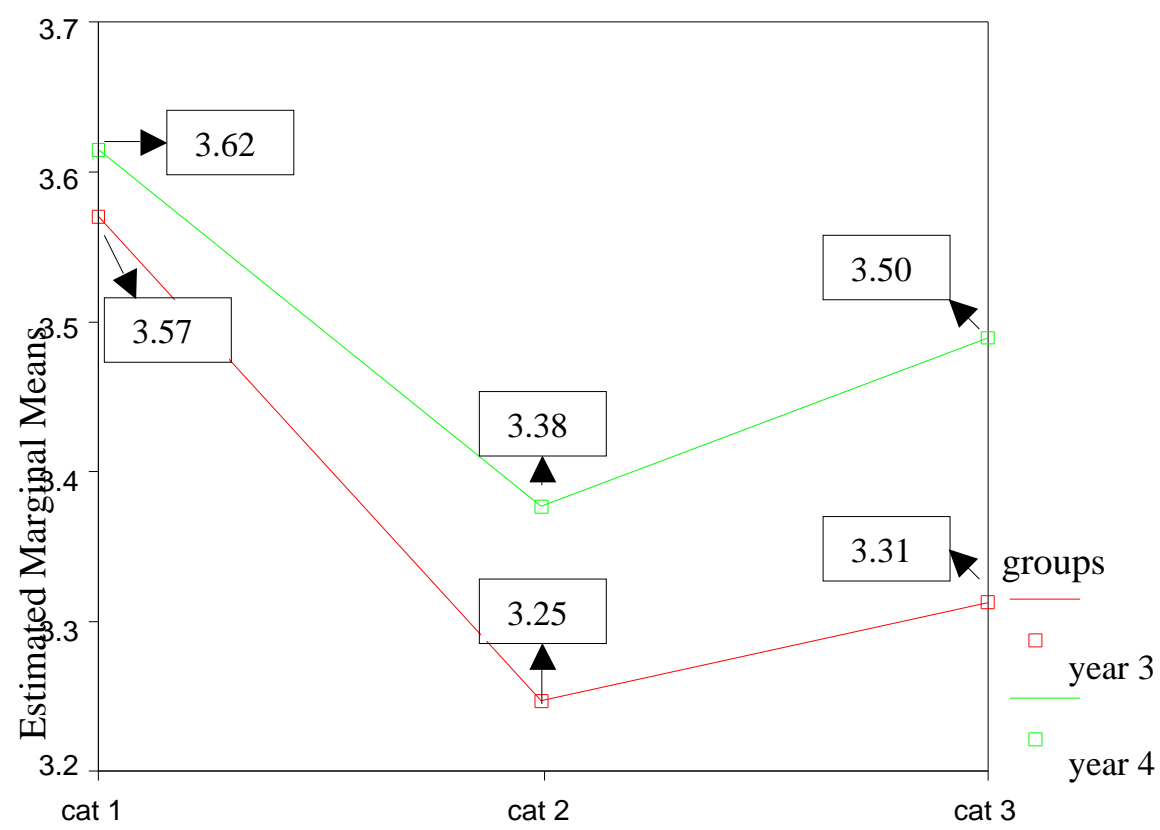

categories of questions 


\section{Diversity Essay Question Data Report and Analysis}

In order to access what the students have learned from the diversity strand in the teacher education program and to answer the second research question, the researcher used the "Essay Questions" for measurement qualitatively. The results of the measurements further support the results of the Diversity Questionnaire.

Table 3 shows the primary result of the data analysis of the Diversity Essay Questions for both Year 3 and Year 4 groups. The total number of participants of Year 3 group is 90, with 79 females and 14 males. The total number of participants of Year 4 group is 59, with 50 females and 9 males.

Table 3. Idea Units for Year 3 and Year 4 on Diversity Essay Questions

\begin{tabular}{|c|c|c|c|}
\hline Questions & Idea Units & Part & ants \\
\hline $\begin{array}{l}\text { 1. Please describe how } \\
\text { multicultural/diversity } \\
\text { perspectives you have }\end{array}$ & $\begin{array}{l}\text { 1). The Multicultural/ diversity } \\
\text { perspectives the students have } \\
\text { learned: }\end{array}$ & $\begin{array}{l}\text { Year } 3 \\
\text { N. } 90\end{array}$ & $\begin{array}{l}\text { Year } 4 \\
\text { N. } 59\end{array}$ \\
\hline make a difference in helping & A. Diversity and multiculturalism & 20 & 10 \\
\hline you to better understand and & B. Cultural Uniqueness & & 1 \\
\hline $\begin{array}{l}\text { respond in a sensitive } \\
\text { manner to the needs of }\end{array}$ & $\begin{array}{l}\text { C. To be less prejudiced against } \\
\text { specific groups of people }\end{array}$ & & 1 \\
\hline $\begin{array}{l}\text { economically and culturally } \\
\text { diverse backgrounds? Your }\end{array}$ & $\begin{array}{l}\text { D. Stop prejudice and treat } \\
\text { students equally }\end{array}$ & 8 & 2 \\
\hline attitudes? Your knowledge? & E. Social Economic Status & 7 & 3 \\
\hline commitment? & F. Stereotypes & 1 & 3 \\
\hline & $\begin{array}{l}\text { 2). Their attitudes and beliefs: } \\
\text { A. Do not make assumptions }\end{array}$ & & 1 \\
\hline & B. Open-mindedness & 6 & 8 \\
\hline & $\begin{array}{l}\text { C. Provide caring classroom for } \\
\text { those students from families of } \\
\text { low SES and diverse } \\
\text { backgrounds }\end{array}$ & 6 & 4 \\
\hline
\end{tabular}




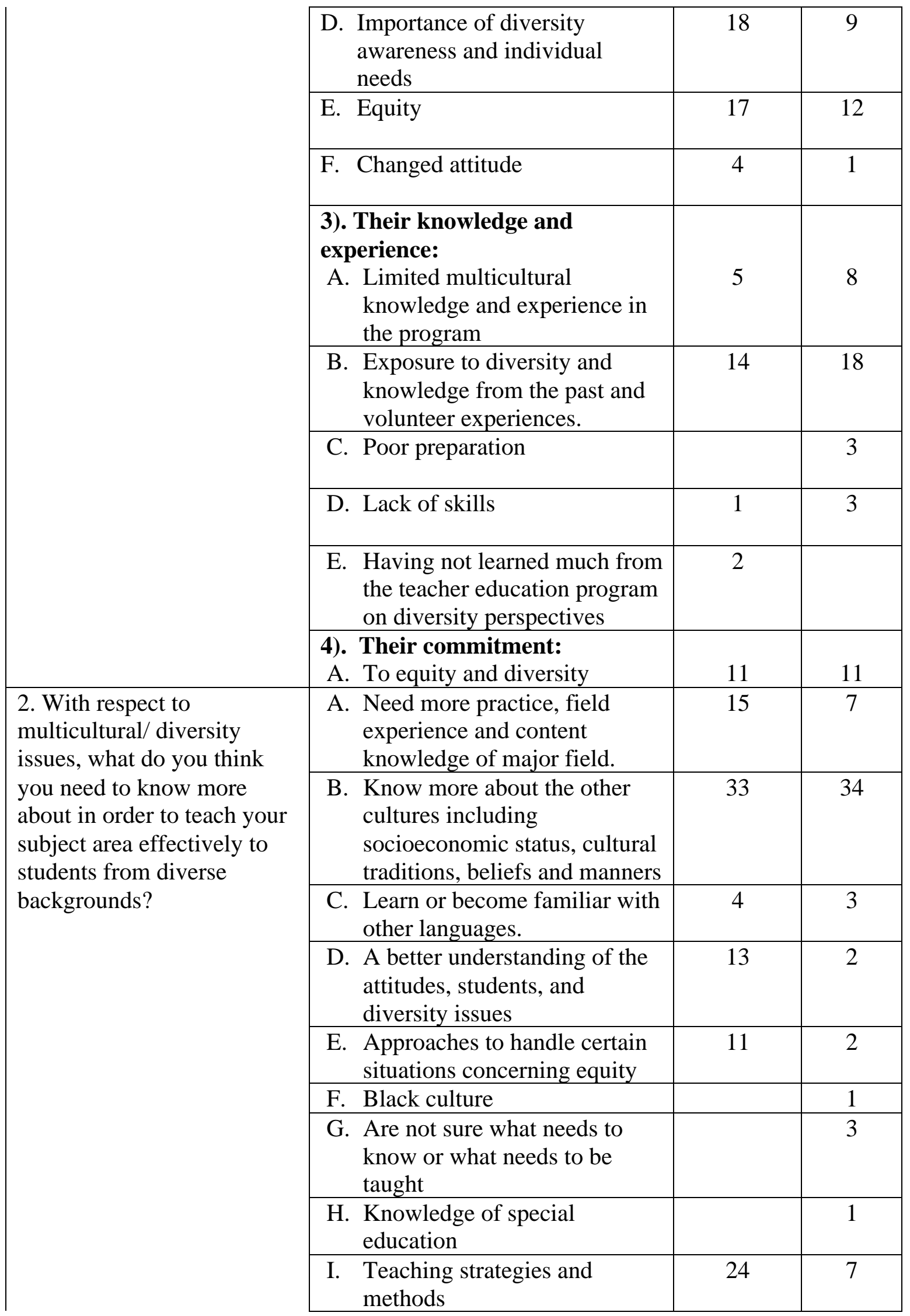




\begin{tabular}{|c|c|c|c|}
\hline & $\begin{array}{l}\text { J. Do not need to learn or know } \\
\text { more }\end{array}$ & \multirow[t]{2}{*}{2} & 1 \\
\hline & K. Others & & 3 \\
\hline \multirow{12}{*}{$\begin{array}{l}\text { 3. From your experiences in } \\
\text { the field, describe } 3 \\
\text { situations you came across } \\
\text { that make you believe that } \\
\text { diversity awareness is an } \\
\text { important component in } \\
\text { our education: }\end{array}$} & A. Faulty labeling & 2 & 1 \\
\hline & B. Exclusion & & 1 \\
\hline & C. Name-calling or teasing & & 3 \\
\hline & D. Gender bias & 1 & 2 \\
\hline & $\begin{array}{l}\text { E. Ignorance or misinformation } \\
\text { of diverse traditions and } \\
\text { cultures }\end{array}$ & & 1 \\
\hline & $\begin{array}{l}\text { F. Race } \\
\text { a). Racial Tension } \\
\text { b). Racism } \\
\text { c). Interracial problems } \\
\text { d). Stereotypes }\end{array}$ & $\begin{array}{l}3 \\
1 \\
1\end{array}$ & $\begin{array}{l}2 \\
2 \\
1\end{array}$ \\
\hline & $\begin{array}{l}\text { G. Inclusion of special needs } \\
\text { children }\end{array}$ & 10 & 5 \\
\hline & $\begin{array}{l}\text { H. No evidence of consideration } \\
\text { of multicultural issues }\end{array}$ & 1 & 2 \\
\hline & $\begin{array}{l}\text { I. School space and minority } \\
\text { students }\end{array}$ & 2 & 1 \\
\hline & $\begin{array}{l}\text { J. Response from the } \\
\text { administration to diversity }\end{array}$ & & 1 \\
\hline & $\begin{array}{l}\text { K. ESL issues } \\
\text { a). ESL or LEP students } \\
\text { b). Not understand students' } \\
\text { languages }\end{array}$ & 13 & $\begin{array}{l}6 \\
2\end{array}$ \\
\hline & $\begin{array}{l}\text { L. Social economic status } \\
\text { a). Children from families of } \\
\text { different social economic } \\
\text { status } \\
\text { b). Children from lower SES } \\
\text { families needed to help at } \\
\text { home or at school } \\
\text { c). Free lunch program } \\
\text { d). Not sensitive about the } \\
\text { economically } \\
\text { disadvantaged students } \\
\text { e). Inadequate clothing } \\
\text { f). Lack of supplies at home } \\
\text { g). Health care and hygiene }\end{array}$ & $\begin{array}{l}2 \\
1 \\
1\end{array}$ & $\begin{array}{l}2 \\
1\end{array}$ \\
\hline
\end{tabular}




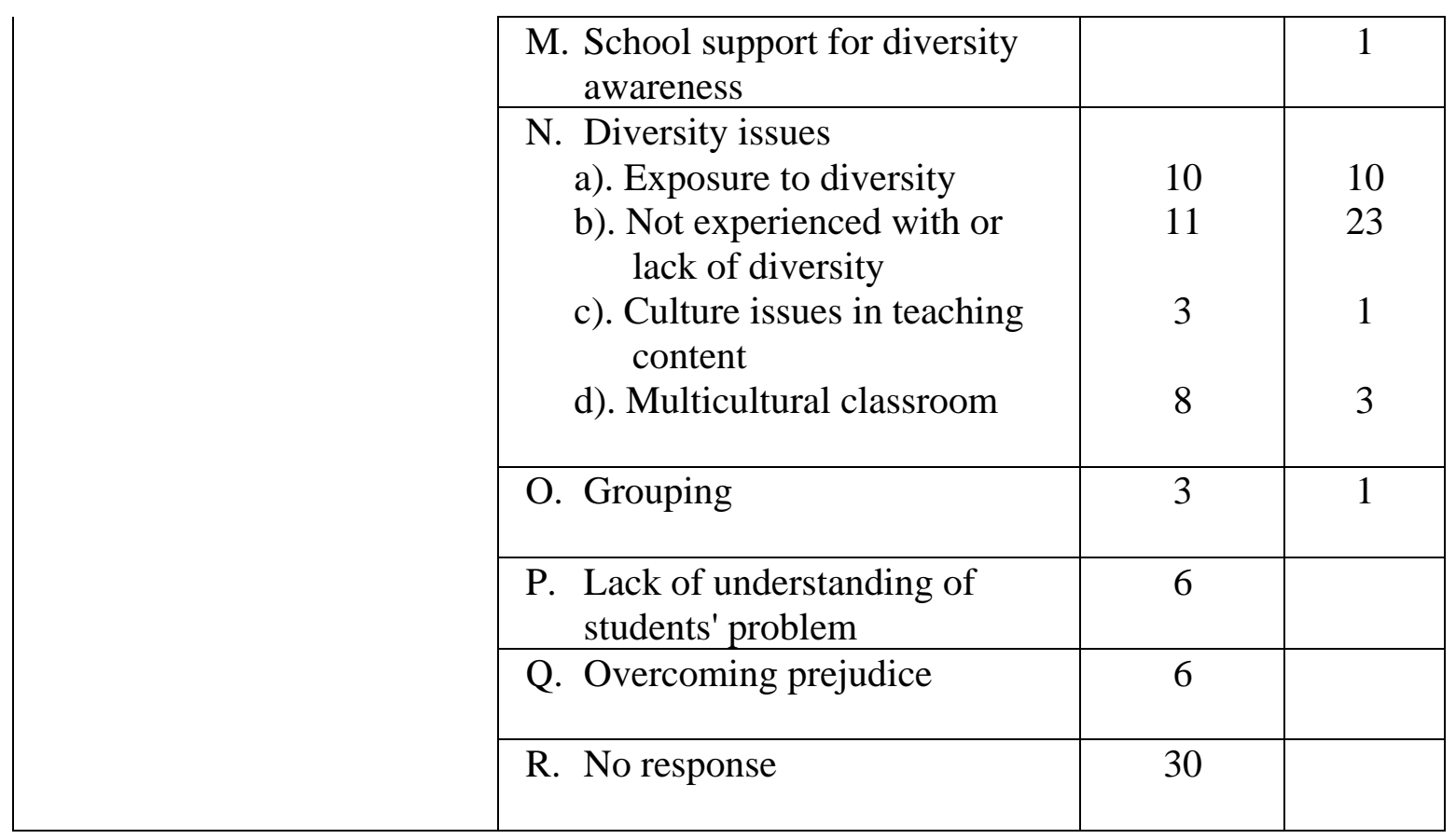

\section{The Thematic Domains:}

When the idea units from the responses of the Diversity Essay Questions were compared, several conceptually distinct thematic domains emerged. These thematic domains answered the second research question of this study: What have the students learned from the Diversity Strand? The following thematic domains of both Year 3 and Year 4 groups, which emerged from the analysis of the idea units, are explained with examples of responses from the participants of both groups.

\section{The Perspectives the Students have Learned}

The participants of this study realize that the multicultural/diversity perspectives they have learned from the diversity strand really make a difference in helping them to better understand and respond in a sensitive manner to the needs of students with disadvantaged economically and culturally diverse backgrounds. Twenty participants in Year 3 group and ten participants in Year 4 group agreed that they had learned diversity 
and multicultural issues from the Diversity Strand of the five-year teacher educational program. What they had learned really helped them to understand their students better. They mentioned that they have learned from the courses and field experiences about the issues of social economic status and called for treating students equally and stopping prejudice.

The following are examples of what they said concerning the perspectives of diversity and multiculturalism they have learned:

\section{Year 3 Group:}

"The perspectives I have learned have helped me understand that all children have different needs and that and you have to take into consideration where the children are coming from when teaching them."

"So far the perspectives I have learned have helped me to realize I need to be more aware of students' needs and cultures. It helped me to consider my own feelings and ideas toward multiculturalism and also to consider how I will teach this topic in the future."

"The multicultural/diversity perspectives I have learned have helped me to understand that children are all different, and all require different kinds of instruction. I feel that it is important to understand these differences and to provide a learning atmosphere for all of the students."

"The multicultural/diversity perspectives I've learned really make a difference in helping me to better understand the students because it allows me to know what students are at risk and what special instruction they might need to help them learn more." 
"The perspectives I have learned have enabled me to accommodate the needs of all students, regardless of their background. They have helped me realize that the curriculum must be adapted to the needs of every student."

"I have come to understand that involving diversity and multiculturalism in the classroom is not only important for showing respect to certain groups but it allows them to have a great self-image. Mental health about oneself is important to being able to learn; if someone feels they are inferior or rejected how can they be in the mind-set to learn?"

\section{Year 4 Group:}

"We have been taught how it is essential to treat all students equally no matter what their SES or cultural background. It has been emphasized how the teacher's attitudes of children really impact those students and cause great harm if the attitude is negative. Due to this it will be a priority that I treat all students with equal respect and strive to help all students grow as learners."

"I have learned to be more aware of various diversities, and the prejudice that surrounds them. I am more aware that some of my students are economically disadvantaged."

"Having an awareness of diversity is very important in understanding students. Being able to effectively reach your students involves knowing their needs and their abilities. Making every student feel as though they are equal will encourage students to be successful." 
Some participants in both Year 3 and Year 4 groups indicated that they had learned how to stop prejudice and treat students of diverse background equally. The following are examples of their statements:

\section{Year 3 Group:}

"My perspectives of multicultural/diversity make a difference in that they allow me to teach all of my students equally, regardless of their culture or background." "I have learned that all children deserve the same treatment. It shouldn't matter how much money their family has or what color their skin is. I have observed that this isn't always the case, that some teachers treat kids differently. It is my goal to always treat all the children with the same respect."

"I've become more aware of each student's different needs, mentally, socially, physically, economically, culturally, spiritually, and emotionally. I've learned to have a more open mind and not to jump to conclusions."

"My positive experience has not only encouraged me to become a teacher but to have a personal understanding that these children regardless of their social or ethnic status are human and have most of the same needs!"

\section{Year 4 Group:}

"I was raised to pretty much treat people equally. I was, however, fairly naïve about the prejudices that some people do have. I have learned about how to deal with those people (as students)."

Some participants in both Year 3 Group and Year 4 Group indicated that they had Learned and been exposed to the issues of social economic status in the program that 
help them to be sensitive to students' needs. The following are some examples of what they said:

Year 3 Group:

"It allows me to understand that children from diverse backgrounds or economically disadvantaged students may need extra or different styles of teaching for their success."

"I feel that I have been exposed to economically, cultural differences and therefore I am able to be more responsive to students that fit this category." "Realizing the difference in students has made more aware of how teaching will be affected -- students from economically disadvantaged backgrounds tend to need a little more help in school not all the times but in some instances." "I think the multicultural perspectives I have learned have made a difference in the way I interact with students. I think patients and tenacity (not giving up) are key when dealing with students that may have a hard or true understanding the material covered because of cultural differences or low SES."

"I have learned that students who are economically disadvantaged may need more help in areas of academics. They may not have the educational materials at home to help them achieve more. They may also not have the parental support and encouragement needed. Many times these disadvantaged students need one-on one tutoring and by knowing what I know now, I can better serve these students." "A child coming from an economically disadvantaged background needs extra 
concern and motivation while learning. The child most likely is not getting this at home so they need this in the classroom."

"I have observed that children from economically disadvantaged families often have uneducated parents and therefore receive less help with homework, math and reading skills at home. These children require more assistance and time in the classroom, to compensate for the lack of help at home."

\section{Year 4 Group:}

"I have learned that children cannot help it if their families are economically disadvantaged. As teachers, it is our responsibility to be sure that all of our students have a fair chance to learn and succeed."

"School X is extremely diversified economically from what I am used to. I am now more aware of how things are regarding economics in different areas and statuses."

\section{Their Attitudes, Knowledge and Commitment}

The idea units of the essay questions suggest that the students have developed and formed their positive attitudes toward diversity within the progress of their teacher education program and their field experiences. They believe that diversity awareness and individual needs were very important issues for both students and instructors. They also believe that equity is the heart of diversity in teaching practice. As an instructor teaching in a classroom with students of economically disadvantaged and culturally diverse backgrounds, open-mindedness would be crucial. The idea units also suggest that the students from both groups have some valuable exposure to diversity and knowledge in their past and field experience. But at the same time, some students from Year 4 Group 
mentioned that there were limited multicultural knowledge and experience in the fiveyear teacher education program. Some students even mentioned that they had poor preparation for diversity. This is a very good warning signal to the program coordinators and instructors that they need to look into the program and see why the students say so, and if they need to reevaluate the program or the design of the diversity strand.

Eighteen participants in Year 3 Group and nine participants in Year 4 Group stressed the importance of diversity awareness and individual needs. The following are examples of what they said:

Year 3 Group:

"Children are all different, and all require different kinds of instruction. I feel that it is important to understand these differences and to provide a learning atmosphere for all of the students."

"I think that it is important to have a good understanding of diversity and how it effects students. I understand that it is important to be aware of cultural differences then teaching and try to accommodate everyone into your lesson plans."

"I think the best way to teach multicultural/diversity is to include everyone when you teach, as in using examples from all cultures and being a good example. They probably haven't formed stereotypes yet and you can guide them in the right direction by expressing your feelings as acceptance to everyone."

"I think it is good to be sensitive to differences, but not so much that the child feels singled out or uncomfortable."

"Learning about students from diverse backgrounds makes me aware of their 
special needs, while making me realize how crucial it is not to term them as special students. Lessons need to be adaptable to all students and help all learn, not just the students with or without special needs."

"My attitude though has not changed. I believe that students all have the same potential. And we need to find a way to unlock that potential."

"As a secondary education/Spanish major, my specialization is based on diversity. The Hispanic culture is full of beauty and magical history. I want everyone that I teach to appreciate its diverse culture."

"My multicultural perspectives have made me realize that children learn differently. If you relate subject matter to their culture the children can relate better to the info and intern learn better."

"You must recognize the needs and varying attitudes of your students, in their entirety, and adapt to their needs. Concern and patience were my two most challenging factors. Some students require more attention than others, so you must find a method of instruction that was beneficial to everyone. You can't give up at any point, because the students can detect this negative attitude and they will react in the same manner."

"Teachers, for example, cannot expect a homeless student to draw a picture of his/her bedroom. Being aware of these types of things has made me realizing the importance of my sensitivity in the classroom. I will try even harder to relate to all the individual personalities and cultures represented in my classroom." "I have learned that children have different needs and different teaching strategies must be used depending on a child's background. I used to be unsure of teaching 
children different than myself (almost scared), but now view it as a challenge I can overcome."

\section{Year 4 Group:}

"I definitely feel that multicultural education is important. I have had some experience with economically disadvantaged and I feel I could work alright in that situation."

"I have learned that this institution needs to help develop our awareness of multicultural issues by offering classes that will enable us to better appreciate people from diverse backgrounds. It is frustrating to both students and educators when cultural differences are misunderstood."

"I feel that it is really important to let the students know that the culture they are from is important."

"If you understand the situations and different cultures of your students you help them to learn more. I think that diversity is important. It helps people to be aware of the cultures around them. Multiculturalism will be a part of my curriculum no matter what grade I teach. I feel it is extremely important to familiarize students with the world around them."

"There are going to be various types of children in your classroom, and we as teachers need to meet children's needs. We need to teach our classes to be accepting of all children and it is important to note that we are all different, but we are all special. Economic diversity is also a factor in the school system." "I think teachers who are prejudice free and have the desire to help students learn will be successful. You need to foster an attitude of acceptance, respect, and 
understanding for others."

Seventeen participants in Year 3 Group and twelve participants in Year 4 Group stressed equity. The following are some examples of their statements:

\section{Year 3 Group:}

"I believe that each student needs to be treated equally. Each student is so different and I believe you have to take each as an individual. I will respect these believes and attitudes and will not judge them because they are different than I am."

"I have observed that when working with students of differing economic backgrounds and races, all must be treated equally. Not all expect this to be so, but it is a great injustice to fail to do this."

"In my school, I have majority of white lower income children, but there are about 30\% African American students too. The thing I find most important is to be as fair as possible to everyone no matter what. Good or bad, poor or wealthy, black or white, these kids all deserve to be in school and learn something. I think that it is something all teachers should understand."

"To be different from the majority would be extremely difficult and making them feel accepted and comfortable would be my main goal."

"I think that I learned that all students have different backgrounds and that if you are patient with all of them then all students would be better off. Every student no matter their background should be treated equally."

"I realize that each student is different, and no matter what his/her background is, 
they should receive the same opportunities."

"My attitude toward these kids is this: some things that cannot control (race, finances) but other things they can (behavior) and I hold them equally responsible for what they can control."

Year 4 Group:

"When you first see a room full of different looking kids you try to see how differently they really are. But I have come to the conclusion that they are all just kids and they all have their own unique identities and problems regardless of their ethnicity."

When the participants were asked their attitudes and beliefs on diversity, six participants in Year 3 Group and eight participants in Year 4 Group indicated that they had learned to be open-minded to students of diverse backgrounds. Here are some examples of what they said:

Year 3 Group:

"I have learned to be clear with my directions and to avoid examples contain cultural bias. I have to keep an open mind and learn from all the children." "Remaining open-minded is a vital trait when dealing with diversity." "You have to keep an open mind. Not every child comes from the same background as I do. Every child is raised differently and these differences make every child unique. When dealing with diverse background, try to understand and get to know the differences."

"I had an attitude of open-mindedness. When the children asked questions. I tried to be very forward." 
"My attitude is more open from my knowledge gained over the past four semesters. From that I attain skills to know what to do, as well as commitment to my students."

Year 4 Group:

"My attitude is one of open-mind and let the children feel comfortable with myself and approaches to teaching."

"By working with school X, I haven't experienced much diversity. I do though feel that growing up with culturally diverse people in my class, I am extremely open-minded and can handle myself in different situations regarding that matter."

"I know that I need an open mind, a positive attitude, and willingness to help everyone. Even though people look or act different on the outside."

"I feel that my attitudes would not get in the way of my teaching. I am a very open-minded person. I want to be able to help my students learn as much as possible. I also feel that I will learn from them. I will be incorporate their culture into my classroom!"

\section{Their Knowledge and Experience:}

Forteen participants in Year 3 Group and 18 participants in Year 4 Group indicated that their exposure to diversity and knowledge came from their past and volunteer experiences. The following are examples of what they said:

Year 3 Group:

"By now, the sensitive matters I have learned have not come mainly from the education courses, except some in EDUC. 100. Most of my experience has come 
mostly from working at a camp outside Chicago where some of my campers came from urban parts."

"I volunteered at a school which included a wide span of economic situations. It made me much more sensitive to all the children's needs, not just specifically the advantaged or disadvantaged. We had to really work at getting all students working and cooperating with each other."

"While volunteering my time in many different schools and preschools, I came across many background of children. Working with such economically and cultural diverse children has helped me develop more sensitively to the variety of different needs that encompasses a classroom. Having this knowledge has helped me also in working with the children differently and in unique ways because of each child's special needs."

"Working as a volunteer in the Kaleidoscope Program at X Middle School gave me some insight on diversity, as it is a program designed for kids who have low SES and need a place to be in the attentions. As I learned about diversity, I grew more comfortable interacting with them, and I began to understand why they behaved the way they did."

"Being at X Elementary has brought me in contact with many foreign children that can't speak/write English well. Their culture is very different so you have to always be proper. It has made me realize how important it is to have training to work with children with special needs whether LEP or handicapped or lower social income children." 
Five participants in Year 3 Group and eight participants in Year 4 Group indicated that they had limited multicultural knowledge and experience in the program. Although the number of students is not large, we need to give special attention to what the students said because they represent part of the participants of this study. The following are examples of what they said:

\section{Year 3 Group:}

"I have not had much experience with dealing with diversity. Until I came to college I had hardly been exposed to diversity. Now I feel that I have a good hand with dealing with diversity in the classroom and with disadvantaged children." "My experience is based previously in readings, lectures and theories at this point, as I have not yet begun tutoring in schools (I will this week). I do think EDC 100 helped make me more sensitive to minority issues. The only problem is that such a class is always directed by a professor who may not give a balanced argument for each side of an issue."

"I do not have much experience with diverse students. I had one child in my Energy Express class that was different from the other students."

\section{Year 4 Group:}

"Throughout my classes, I feel like we have had very little practice in dealing with diverse students. My knowledge of multiculturalism is extremely basic." "I really haven't learned all that much about multicultural/diversity perspectives thus far. I don't know much about other cultures because my hometown is predominately white and of Italian descent."

"I have not really been taught how to exactly deal with multicultural/diversity 
except to be make aware of it. I have been informed that it is an issue and as a educator I need to be sensitive to it."

"My personal experience with economic disadvantage makes me more knowledgeable and comfortable with children in this category. As for cultural diversity, I try to be open and meet the needs present, but I do not possess much information or specific skills in dealing with children of culturally diverse backgrounds."

Three participants in Year 4 Group indicated that they got poor preparation in teaching students from diverse backgrounds. The following are examples of what two of them said:

Year 4 Group:

"To be quite honest, I feel I have not had enough (if any) classes that focused on diversity. Of course it has been mentioned in many of my classes, but that has been the extent. I feel like it has been glossed over and as a result it is a bit of a mystery to me. I have not seen any examples of really in-depth teaching. Most of the discussions I have heard concerning diversity have been very superficial." "My school is very rural. The SES is poor to middle class families. It's a very small school. My school really has no diverse background, and I have no experience with diversity in this school." 


\section{Their Commitment to Equity and Diversity}

Eleven participants in Year 3 Group and eleven participants in Year 4 Group indicated that they are committed to equity and diversity. The following are examples of their statements:

Year 3 Group:

"I believe that I have a high commitment to helping and teaching equally. I think this will be easier because I am so open-minded."

"I have no problems with working with people from a different culture and I am committed to bettering my students learning environment in any way possible. "What I have learned has definitely made me more committed to teaching in multicultural settings."

"I am now more open to possibilities and understand that there are extensive differences from student to student since I have studied diversity. I feel my commitment has grown stronger because of my will to succeed."

"I feel that I am more comfortable with teaching students of multicultural backgrounds. I know that some do have problems in school because of what they were taught before. I feel that I am ready to teach these children and I am committed to helping them."

Year 4 Group:

"I'm committed to the fair and equal treatment of a culturally diverse classroom." "I believe I have the skills and commitment to teach diversity to every classroom, no matter what the population." 
"My commitment to students grows each year. I am a part of the teacher education program. By being exposed to many diverse backgrounds of students, I have come to be more tolerant and respectful of other attitudes and perspectives." "My students are also from rural economically disadvantaged homes. This makes a difference in examples I use and in certain ways that I teach. I respect these students just as I would any student. I am, therefore, as committed to them as I would be to any student."

"I am committed to helping everyone and giving all students a deserved education."

"Being around children of poor home environments only reinforces and strengthens my commitment to make every child feel loved and of value. It also make me try even harder to give them the skill they need to be successful."

\section{What They Need to Know More About}

The data of essay questions suggests that the students from both Year 3 and Year 4 groups are eager to know more about other cultures including socioeconomic status, cultural traditions, beliefs and manners in the rest part of their teacher education program. They also want to know more about teaching strategies and methods and need more practice, field experience and content knowledge of their major fields. The students from Year 3 Group indicated that they need to know more about how to have a better understanding of attitudes, students, and diversity issues especially to know more about the approaches to handle certain situations related to equity. 
Thirty-three participants in Year 3 group and thirty-four participants in Year 4 group indicated that they needed to know more about the other cultures. The following are examples of what they said:

\section{Year 3 Group:}

"In terms of multiculturalism, I feel that I need to learn more about other cultures such as native Americans and languages. A better understanding of all cultures would help me to develop successful lesson plans."

"I feel I need to learn more about each cultural background I'm dealing with in a classroom, so I can relate to my students better. By doing this, I would also get to know my students better."

"I think that I need to know more about other cultural backgrounds and get to work with a more diverse group of students. I think that by doing that I will learn a lot about other cultures and beliefs. Moreover, with this knowledge I think that I would be a more effective teacher."

"I would need to know more about their personal backgrounds. How much of their diverse culture have they already had in their lives. Also I would need an understanding of the general culture they are from."

"I need to engage in some serious research about various cultures before I can teach anything about them. I would like to learn different practices and customs so I can relay more than "book facts" to students."

"I need to learn more about specific cultures. There seems to be such a prominent influence to teach about black and white culture. But there are other cultures and backgrounds needing to be represented. I need to learn more about bilingualism, 
Hispanic culture, Asian American culture, American Indian culture, etc."

\section{Year 4 Group:}

"I think I need to know more about cultural traditions and manners. For instance, in the US it is polite to look at someone when you speak. In some countries, looking away is a sign of respect that could be taken as rudeness. There are many that I am sure I'm not aware of."

"I would also like to know more about my students' backgrounds and beliefs. In other words, how do I find out such info in order to prepare myself for any problems may arise regarding these aspects."

"I would like to know more about the customs of different cultures. When I teach a group of diverse learners I do not want to offend/insult anyone from different cultures."

"I need to know more in depth about the various cultural traditions and attitudes that many have an effect on the student's learning. This understanding will also lead to better interaction with the parents."

"I think it would be nice to know some of the customs that the children come to class with. They may do things I don't like or agree with, but they also may not understand they are doing anything wrong. We need to be more patient, accepting and open to all children."

"I think I need to know more about individual cultures. I would like to know what life is like in the various cultures that might be represented in my classroom. I know it is not likely to know every culture in the near future, but I do want to learn the basics of as many cultures /backgrounds that I can, in order to know all 
of my students better."

"I need more knowledge of cultural beliefs and traditions. I think that more knowledge of other cultural backgrounds would make it easier for me to incorporate multicultural curriculum into my class."

Twenty-four participants in Year 3 Group and Seven participants in Year 4 Group indicated that they needed to know more about teaching strategies and methods. The following are some of the examples of what they said:

\section{Year 3 Group:}

"I need more examples of scenarios that could take place in a classroom in order to understand what actions can be taken to help each student."

"Luckily math is not cultural, but the teaching is. I'd like to find out more about the general learning styles and teaching styles of multicultural classrooms since I know not everyone learns the same way."

"I need to know how they would best learn the material. Different teaching approaches that I can apply to the classroom so all students have an equal chance of learning the material."

"I also need to know a variety of teaching styles so I will be able to effectively teach students from diverse backgrounds."

"I think I need to know which students are at risk and different teaching methods that different types of students seem to respond to better."

"All the different ways that children learn and how to teach according to these different styles. What are the cultural norms that I may encounter and the best 
ways to promote diversity."

"When it comes to teaching Physical Education, I believe learning about the different culture's taste for sport and a willingness to try these out in class is key." "How students from different cultures learn best and what teaching methods may not work for certain cultures. Because I want to teach science, I would like to know the views and beliefs of other cultures towards different science topics/subjects (what they stress, what they feel is important to know, any myths that may exist)."

\section{Year 4 Group:}

"It is important to be aware of the accomplishment all races have made in the field as well as how the students from different backgrounds understand and learn the best."

"I think I need to know more about which teaching strategies are most effective for students with specific backgrounds. I know that we all learn differently, but I also recognize that specific cultures a group of students may respond more positively to one specific method of instruction. I need to become better acquainted these methods."

"I think I need to know more about teaching strategies to use to help multicultural students feel a part of the class without drawing negative attention to them, especially with LEP students (ESL)."

In responding to the second essay question, 15 participants in Year 3 Group and 7 participants in Year 4 Group agreed that they needed more practice, field experience and content knowledge of major field. The following are examples of what they said: 
Year 3 Group:

"I think there is really no substitute for experience. Dealing with people from diverse backgrounds requires an open mind that is free of prejudice (at least as free as possible). I have such a mind but have not really gone through an actual experience of teaching a diverse group of pupils. It will be partly trial-by-fire." "I believe every teacher-to-be should educated through classes, seminars, hands on experiences, etc. Training is essential to overcome stereotypes presented in every day life."

\section{Year 4 Group:}

"I am a Secondary English Education major. It is vital that I understand and am knowledgeable on these issues. My main focus will be towards literature. Therefore, I must be able to teach well to the entire class. Which is where I will run into issues of who gets it and who doesn't. Currently, in my C\&I 224 we concentrate deeply into diversity issues."

"I think that experience is the key and actually being in the situations will better prepare you to face diversity within our classroom."

"I think that the only way to truly learn about other cultures is to experience them first hand. Books don't do much but confuse me. A teacher should be well educated about all races."

Thirteen participants in Year 3 Group and two participants in Year 4 Group indicated that they needed to learn how to better understand the attitudes, students, and diversity issues. The following are examples of what they said:

Year 3 Group: 
"How to get all students of every culture interested not just in school work but in other aspects of the school as well. Also, how to make sure my class is tolerant to different cultures and races."

"I think as a teacher it is important to educate yourself in many cultures and different backgrounds. The main key is to get to know and understand your students."

"I feel that I need to know more about students of different races. It will make me a more effective teacher and I will be able to accommodate to all students needs. "I think people need to know and understand the background of those people a little more. I believe, in order to teach a child the differences between cultures, teachers need to know, understand, and respect the culture the child doesn't understand."

\section{Year 4 Group:}

"I would need to know anything about multicultural issues to be able to teach students from diverse backgrounds. We have little to no training in this area. We are not taught much about other cultures."

Eleven participants in Year 3 Group and two participants in Year 4 Group

indicated that they needed to know approaches to handle certain situations concerning equity. The following are some examples of what they said:

\section{Year 3 Group:}

"I think I need to know more about the things that can insult or offend diverse students. For instance, some of the things about their culture that they don't want to talk about may not seem offensive to me but could offend them." 
"I think that I need to know things that are common in other people's backgrounds so that I don't offend anyone (or try not to) by making or doing something that I really not accepted in their culture. I want my students to feel comfortable in my classroom and I'd try to find anyway possible to make them feel at home since they are at school for a good part of the day."

"I believe that in order to teach successfully, one must address what the child already knows about the subject regardless of race and expand on the aspects that may be less clear."

"What they know about the Hispanic culture? I want the other students with diverse backgrounds to share their cultures and all that is unique about them." "You must understand how the student learns. What approach would make the child understand. Also when teaching history for instance how does the history they are learning pertain to their background. You have to stretch yourself beyond what you know and understand what they know."

"I would like to know how to handle situations where children ask specific questions. Example, how to make a different child stand out?"

\section{Year 4 Group:}

"I have been exposed to a good deal of information dealing with fostering a positive attitude toward diversity. However, I have not been exposed to much info dealing with how to handle negative situations/conflicts."

\section{The Situations in the Field}

The data suggests that participants from Year 4 Group have more field experiences than the participants from Year 3 Group. Participants from Year 4 Group 
could give at least one situation in their field experience to show that diversity awareness is an important component in our education while thirty-three percent of participants from Year 3 Group gave no response to this question. That means they did not come across such situations in their field experiences. The situations they came across in their field experiences include working with ESL or LEP students, children from lower SES families needed to be helped at home or at school, and the situations in which the students did not experience with or expose to diversity.

Thirteen participants in Year 3 Group and six participants in Year 4 Group indicated that they came across situations of dealing with ESL or LEP students in their experiences. The following are some example of situations they described:

\section{Year 3 Group:}

"When tutoring at a local elementary school. I came across a student whose $1^{\text {st }}$ language is Spanish. He asked me my name in Spanish. I also encountered a Korean girl who spoke little English."

"Two of my students are from south Asian decent. I believe it is very important to understand where they are from."

"When I volunteered at Scotts Run Settlement, There was a lot of diversity. Many of the children fluently spoke Spanish but were learning to speak English." "So far in my placement I have not really experienced a lot of diversity. But when doing my volunteer work I worked with several English as a second language students and saw the need for varying techniques of teaching basic English." "Teaching a child from China - not being able to use common slang or other English terms they aren't aware of." 
"During my volunteer work I was asked to teach a nine-year-old Mexican boy how to speak English."

"In a high school class, I've came across several international students who can understand English but have trouble speaking it."

"In a kindergarten class the teacher asked her class to bring in a list of things that began with the letter "A". A little girl brought in a list of things in Spanish because she got help from her parents who do not speak English."

Year 4 Group:

"I have worked with several students from Europe and Asia that do not speak fluent English. I felt that I needed to make myself more aware of their "home" culture to be able to connect with them."

"In EDUC 260, Literacy for Primary Grades, one girl in my site-based teaching group was an ESL student and had an extremely limited ability to communicate in English. It was a great struggle."

Eleven participants in Year 3 Group and one participant in Year 4 Group indicated that they came across situations in which children from lower SES families need to helped at home or at school. The following are some example of the situations they described:

Year 3 Group:

"A young man who was a senior was still in applied algebra I. He was from a lower SES and walked about 1 and half miles to class. It would have been easy to interpret his behavior in class as "acting out" or "bad" but it was instead a cry for help and love." 
"My school has some lower class children in it and they need the extra support of a caring, stable person and I can give that to them by being there as a consultant." "Saw how students from low SES often were further behind the rest of the class and needed extra help to catch up."

"Working with students of all economic backgrounds and ethnic diversities made me realize everyone is special in different ways. Working with the lower class students I learned that they were very defensive to cover their insecurities. They tend to be very loud to keep the center of attention and they very seldom let their guards down."

"While volunteering in a public school, I had the opportunity to work with a child who had a low reading level. He was from a low-income family and his home life was unstable. This made me more aware of his needs and issues that might come up when helping him."

"A little girl who was put in the first grade was unable to read and had no desire to sit and pay attention. She had moved (from state to state) around a lot and the teacher had never met her mother. She needed a lot of extra attention."

\section{Year 4 Group:}

"There are many children in my class and each one is different. I can only think of on situation that sticks out. One student came to me and told me he was leaving school early that day so that he and his mom could go to the laundry mat to wash their clothes. What is the response a teacher should give?" 
Eleven participants in Year 3 Group and twenty-three participants in Year 4 Group indicated that they did not experience with diversity or lack of diversity. The following are some examples of what they said:

\section{Year 3 Group:}

"I have not encountered any other situations in which I noticed a diversity issue."

"I have not yet come across situations involving multicultural backgrounds."

"I really haven't experienced any situation that deals with diversity."

\section{Year 4 Group:}

"I have not experienced anything yet. I work at a predominantly white middle school. I hope to gain more experience to more diverse institutions."

"I have not dealt with diversity at all out in the field and I have not witnessed much prejudice of it either."

"There is no diversity at my PDS!! I've seen only one African American and only one Asian American. The school and students have trouble with diversity because they aren't exposed to it, so don't understand it."

"At my school there is no diversity. I have never seen any of my classes study diversity, or even read a book with someone from another culture in it. I believe it is important to learn. The ethnic population of U.S. is rapidly changing and everyone must be aware of and sensitive to diversity."

"Little diversity in my PDS (school X) so I think it is important to open up these issues to them since the students there have never be faced with it."

"It is hard for me to come up with any situations regarding diversity awareness 
because the school I am placed at has approximately a ninety-nine percent of Caucasian population."

"There were no particular situations that I came across. I don't feel like my school is diverse at all !!!"

Ten participants in Year 3 Group and ten participants in Year 4 Group indicated that they do have some exposures to diversity. The following are some examples:

\section{Year 3 Group:}

"I was once tutoring a little girl who insisted on using the word "ax" in place of "ask" because (even though she promised that she understood the meaning and spelling...) that was how it was pronounced in her home."

"In an elementary class, I had several Jewish boys who wore the beanies and the other students didn't understand why."

"At a summer camp, an African American child danced in a way that seemed inappropriate for a child, but that was her cultural expression."

"I had a child who was Jewish and did not celebrate the Christian holidays as the other children in the group did. It was difficult to explain to the class and the child why he had a different religion. We all ended up feeling awkward."

\section{Year 4 Group:}

"1). A little boy at school $\mathrm{X}$ was absent from school for a religious holiday that his family celebrates. The rest of the class wanted to know where he was and so the teacher explained about how everyone has different beliefs and that is ok.(Being different makes us special) 2). I tutored a Chinese boy who would not look at me when I was talking. His teacher told me that was a sign of respect, that 
his parents taught him that. I thought he wasn't paying attention at first. 3). Kids asking questions about the difference in their skin colors."

"1). A little boy could not speak English very well, let alone write it, so when it was time for him to write a story, he wrote a lengthy story in Chinese. 2). The other children wanted to know why he was writing different from them. They became curious. 3). In general, families are not just mom and dad anymore. I have to be careful when I generalize too much. One little boy told me that his daddy was dead. I felt bad, but I should have just said families or someone at home, instead of mom's and dad's."

"A small boy, from another country, is very shy and speaks to very few people. After talking to him a little he began to talk, a little, to me. A boy came into class not able to speak any English. Over time he was able to pick up some language from his peers."

"Comparing School X to School Y helped me see how diversity awareness is an important component in our education. Seeing other cultures succeed greatly --something I had never been able to see. Seeing eye to eye with other students of different races. You want to take interest in them, so they will with you."

Ten participants in Year 3 Group and five participants in Year 4 Group indicated that they came across situations of inclusion of special needs children in their experiences. The following are some examples of how they described:

\section{Year 3 Group:}

"Some of the children I have worked with are diagnosed with ADD. I have been successful working with them, but it takes a lot more patience. They need more 
help than those without ADD."

"One of my students is a hundred percent hearing impaired. It has given me an opportunity to learn how to sign, and it is a really good experience."

"I am working with a teacher who has a class that is mostly children with learning or behavior problems. She has to find ways of teaching that will keep her students' attention. She finds that keeping them busy keeps them focused."

"1). I work with two handicapped children and just watching them try to do the things that come natural to me has really made me aware of others needs and has taught me to be more patient than I already am. 2). Coming across students that can't speak as well as the other children. 3). Coming across students that aren't fully mentally developed as the others."

"Being in special education, there is a lot of diversity. 1). Slowing down the pace for those with physical disabilities. Giving them time to complete activities that involve motor skills. 2). Verbal communication is not always clear. You must be a good listener and don't just blow off someone's idea because you can't understand. They know they have a voice and it is important that we let them communicate." "I have only completed some volunteer work in the field but I did noticed at one location some interaction with disabled youth which was indicative of the different ways teacher must relate to someone who is different."

"I had one student who was LD and constantly wanted separate attention. I had to learn how to prevent her from disrupting the class. I also had to distinguish between her wants and desires of attention."

Year 4 Group: 
"Deaf, blind, and LEP students at X/Y Elementary. All of these children were crucial in the education of all students. It made the students aware of diversity and gave the diverse students a chance to show their special skills."

"In my current placement, I work with a student who has downs syndrome. I had little experience with this condition, and I realize how important it is for me to learn about it."

It brought to the researcher's attention that thirty participants in Year 3 Group did not give response to question 3 . This indicated that they had not come across such situations in the field experiences.

\section{Case Study Data Analysis and Summary}

Case studies instrument (see Appendix C) consists of three cases and questions for each case are designed to test students' ability to identify the theme, problem of the case, and the proper methods and strategies to handle the situations. The total number of participants of Year 4 Group for case study was 60, with 51 females and 9 males. They were in the fourth year of the program. The participants in this study were given the version without the headlines that are at the beginning of each case in italic. These headlines give the key issues for each case. Tables 4, 5, and 6 show the summary of idea units for each case respectively.

\section{Summary of the Idea Units of the Case Studies (Year 4)}

Table 4: Case 1

\begin{tabular}{|c|c|c|}
\hline Questions & Idea Units & Participants \\
\hline \multirow{3}{*}{$\begin{array}{l}\text { 1. What are the central } \\
\text { diversity issues in } \\
\text { this situation? }\end{array}$} & $\begin{array}{l}\text { A. Making assumptions or judgement } \\
\text { based on appearance and stereotype. }\end{array}$ & 14 \\
\hline & $\begin{array}{l}\text { B. Not taking time and effort to get to } \\
\text { know students better. }\end{array}$ & 5 \\
\hline & A. Ignoring the students' & 5 \\
\hline
\end{tabular}


2. What would you suggest for Mr.

McDonald?

\section{problems}

D. Lacking communication between teacher and students.

A. Never assume anything.

B. To apologize to Peter

C. He needs to become more involved with his students.

Table 5: Case 2

\begin{tabular}{|c|c|c|}
\hline Questions & Idea Units & Participants \\
\hline \multirow{3}{*}{$\begin{array}{l}\text { 1. What did you find effective } \\
\text { about Ms. Christensen's use } \\
\text { of literature and movies to } \\
\text { teach values? What might you } \\
\text { change? }\end{array}$} & $\begin{array}{l}\text { A. Effective, interesting, and } \\
\text { different. }\end{array}$ & 18 \\
\hline & B. Not effective & 7 \\
\hline & $\begin{array}{l}\text { C. Things might be changed and } \\
\text { improved }\end{array}$ & 16 \\
\hline \multirow{5}{*}{$\begin{array}{l}\text { 2. Is it appropriate for teachers } \\
\text { to challenge students' } \\
\text { traditional social and role } \\
\text { concepts, especially those } \\
\text { based on family and religious } \\
\text { values? If so, at what ages and } \\
\text { under what conditions? If not } \\
\text { so, give your reasons for } \\
\text { saying that. }\end{array}$} & A. Appropriate & 24 \\
\hline & B. Not Appropriate & 11 \\
\hline & $\begin{array}{l}\text { C. Age or Condition: } \\
\text { 1). At Any age }\end{array}$ & 3 \\
\hline & $\begin{array}{l}\text { 2). At an Early Age (At elementary } \\
\text { level) }\end{array}$ & 8 \\
\hline & 3). Middle School Age and Up & 10 \\
\hline
\end{tabular}

Table 6: Case 3

\begin{tabular}{|l|l|c|}
\hline \multicolumn{1}{|c|}{ Questions } & \multicolumn{1}{|c|}{ Idea Units } & Participants \\
\hline \multirow{4}{*}{$\begin{array}{l}\text { 1. What are the central } \\
\text { diversity issues in this }\end{array}$} & A. Affectional orientation, & 3 \\
\cline { 2 - 3 } & B. Gender & 6 \\
\cline { 2 - 3 } & C. Sexual orientation & 3 \\
\cline { 2 - 3 } & D. Prejudices & 1 \\
\cline { 2 - 3 } & E. Ethnic & 3 \\
\cline { 2 - 3 } & F. Sexuality & 2 \\
\cline { 2 - 3 } & G. Religion & 1 \\
\cline { 2 - 3 } & H. Homosexuality & 4 \\
\cline { 2 - 3 } & I. Gays and lesbians. & 3 \\
\cline { 2 - 3 } & J. Labeling & 3 \\
\cline { 2 - 3 } & K. Sexual preference & 1 \\
\cline { 2 - 3 } & L. Nationality & 1 \\
\cline { 2 - 3 } & M. Name-calling & 5 \\
\cline { 2 - 3 } & N. Racial background & 25 \\
\cline { 2 - 3 } & O. (No response) & \\
\cline { 2 - 3 } & P. Others & 3 \\
\hline
\end{tabular}




\begin{tabular}{|c|c|c|}
\hline \multirow{8}{*}{$\begin{array}{l}\text { 2. Write several } \\
\text { sentences illustrating } \\
\text { how you would handle } \\
\text { the situation. }\end{array}$} & A. Name-calling and labeling is wrong. & 6 \\
\hline & $\begin{array}{l}\text { B. Talk to Xeng and Kim separately and } \\
\text { privately and Xeng apologizes to Kim. }\end{array}$ & 22 \\
\hline & $\begin{array}{l}\text { C. Enforcing class rules and Xeng would be } \\
\text { punished. }\end{array}$ & 12 \\
\hline & $\begin{array}{l}\text { D. Understanding and acceptance of } \\
\text { differences. }\end{array}$ & 6 \\
\hline & E. Assuming things is wrong. & 1 \\
\hline & F. Contacting or Sending notes to parents. & 3 \\
\hline & G. Keeping it private. & 3 \\
\hline & H. Sending both of them to Principal. & 1 \\
\hline \multirow{4}{*}{$\begin{array}{l}\text { 3. Under what } \\
\text { conditions, if any, } \\
\text { would you involve the } \\
\text { class in a discussion of } \\
\text { this issue? What actual } \\
\text { opening state- } \\
\text { ments/questions would } \\
\text { you use to introduce } \\
\text { such a discussion? }\end{array}$} & $\begin{array}{l}\text { A. Conditions under which class discussion } \\
\text { is involved. }\end{array}$ & 15 \\
\hline & $\begin{array}{l}\text { B. Would not get the class involved in } \\
\text { discussion on this issue. }\end{array}$ & 8 \\
\hline & C. Getting class involved in this discussion. & 14 \\
\hline & D. Opening statement. & 6 \\
\hline
\end{tabular}

\section{The Thematic Domains for Case Studies}

The result of the data analysis answered the third research question: How does the students' awareness of diversity help them to plan and implement multicultural education elements in their teaching? The thematic domains of Year 4 Group emerged from the analysis of the idea units. These thematic domains show how the students identify each case and how they handle the situations with the knowledge and skills they have learned from the teacher education diversity strand. The thematic domains also give readers a better idea of how the researcher comes to the conclusions concerning effectiveness of the teacher education diversity strand.

The students' response to the questions of case 1 showed that they identified the problem correctly and answered the questions properly. Fourteen participants identified 
the central diversity issue as "making assumptions or judgments based on appearance and stereotype". The following are examples of the responses from the participants:

"The teacher made assumptions about Peter based on his appearance. While assumptions are a natural human reaction, he should not have acted on those assumptions until he found out the facts. Now he is in an uncomfortable situation, which could have been avoided if he had not over-generalized."

"Mr. McDonald automatically made judgments about his students based on physical appearance ---race, type of dress, etc. He did not ask Peter to tell him anything about himself, but assumed that he must live in one of the poorer neighborhoods because he was a minority. Also, Mr. McDonald did not appear to be concerned about Robert's behavior."

"Mr. McDonald made assumptions based upon the fact that Peter is an African American student. I'm sure Mr. McDonald has got so used to the majority of the school population being minority and poor, that he doesn't take the time to really get to know each student as an individual. Mr. McDonald associates wealthy/middle class with white."

In response to the second question of case 1--"What would you suggest for Mr. McDonald?" Thirteen participants indicated that Mr. McDonald needed to become more involved with his students. The following are examples of what they said:

"That he should talk to Peter and get to know him as a person. He could ask Peter about the trip he took with his family to Europe. He should give Peter his bus pass and maybe apologize for his preconceived notions."

"Mr. McDonald should definitely make a point to become familiar with his 
students, their backgrounds, and socioeconomic status before he makes assumptions based on prior knowledge."

"I would suggest that Mr. McDonald take a little more time in getting to know his students. Making quick assumptions are hard to avoid, but if he makes an effort to get to know his students before assigning them a label, then he will avoid embarrassing situations such as this in the future."

Eight participants suggested that Mr. McDonald should never assume anything.

The following are examples of what they said:

"When you have a new student or see changes in students' behaviors, ask questions. NEVER assume anything. Show interest in your students as individuals."

"He should approach each student equally and not assume things merely from appearance. Mr. McDonald should apologize and explain that he didn't understand Peter's situation."

"That before he embarrassed himself like this again. He could ask the students where they from and general information about themselves. Mr. McDonald should never assume anything about his students without having concrete evidence."

The participants' response to the questions of case 2 showed that the participants held opposite ideas for each of the questions for case 2. The researcher thinks that there are no right or wrong answers to these questions. The most important thing here is to see if they make good and strong arguments to defend their point of view. Eighteen participants indicated that Ms. Christensen's use of literature and movies to teach values 
were effective, interesting and different. The following are examples of the responses from the participants:

"Using literature and movies can be effective in studying values because you will find many examples of stereotypes in them. Becoming aware of how widespread stereotypes are in literature and movies can help you identify them in life too."

"I found Ms. Christensen's use of literature and movies to be very effective in teaching values of respect and diversity to name a few. She used interesting subjects to gain their attention and further their understanding. Her students were able to analyze the movies and literature to see their purpose and other messages portrayed."

"I thought that the use of popular literature and cartoons was a good idea because most students have been directly exposed to these things ---discovering unjust practices in them will "hit closer to home" than merely lecturing on values." "I think Ms. Christensen's use of literature and movies was very effective. It gave the children a chance to explore deeper issues in a fun manner."

Seven participants indicated that Ms. Christensen's use of literature and movies to teach values were not effective for certain reasons. The following are examples of the responses from the participants:

"It seems like children would be interested in the project and have some fun doing it. However, the credibility or extent to which TV's influence has on children/people is questionable. I would make this a point. Not everyone who watches Teenage Mutant Ninja Turtles is violent." 
"Literature and movies are part of popular culture, and students relate well with them. Ms. Christensen is focusing too much on negative aspects, and the students may become discouraged with and distrusting of society. She is also attempting to create a single mind in her classroom."

In response to the question "What might you change?" sixteen participants

indicated that there was something they might change or improve if they were in that case. The following are some examples of what they said:

"I feel that Ms. Christensen has a great idea. If I could change anything, it would be to broaden the spectrum a little. I would have kids critique magazines, billboards, and commercials also."

"The use of literature and movies allowed the children to relate the concepts and values via an entertainment tool they are familiar with. However, I think that because the teacher used books and movies some children may think that these values are fiction rather than real life. The teacher should show students news broadcasts or articles written about true stories."

"She is exposing children to a wide range of media and help them to form their own ideas and values, based on critical thinking. I would probably start the class with a survey and case study problem worksheet to get an idea on where the students were in terms of their thinking. Also, I would look back in history for examples (e.g. Aunt Jemima) and relate it to image of ethnic groups."

The question 2 for case 2 is "Is it appropriate for teachers to challenge students' traditional social and role concepts, especially those based on family and religious values? If so, at what ages and under what conditions? If not so, give your reasons for 
saying that." In responding to this question, twenty-four participants stated that it is appropriate for teachers to challenge students' traditional social and role concepts, especially those based on family and religious values. The following are examples of how they argued:

"It is good for teachers to attempt to challenge social concepts, but they must be sure not to attempt to instill their own values. Teachers \& parents should know that students will form their own values that are not always based on what they see or learn at home or in the classroom."

"I think it is ok for teachers to challenge students' traditional social and role concepts if it kept to a limit. It should not be stressed and strained upon often though. Students need identify with people different from themselves and teachers should prepare them for that, but teachers should not take it to an uncomfortable level."

"When a student's traditional social and role concepts are challenged, he or she has the opportunity to personally explore his or her beliefs. However, teachers should not challenge to the point of discouragement, embarrassment, or ridicule." Eleven participants argued that it is not appropriate. The following are examples of how they argued:

"I think this is a sticky subject to deal with. I really do not feel that teachers should try to persuade students to accompany varying religious values than what they were raised with or used to in the past. If a teacher was to do so there might be trouble with the student's family."

"I think it is not appropriate for teachers to challenge these roles. Everyone has 
different preferences in religious, social and role concepts that parents teach. It is definitely not right for teachers to interfere with the parents' moral rights and ways that they want to pass down. I think it works for all ages. Just because a student might be older, religious and social values do not change in the family." "I don't think it is appropriate for teachers to challenge students' social and role concepts. These concepts of family and religion are learned at home and in the community. I think parents might feel like the teacher is stepping on their toes. The schools can help students maintain these roles and concepts, but not enforce or discourage one or the other."

Ten participants indicated that middle school age and up would be the appropriate age. The following are examples of what they said:

"High school aged (14-18) would probably be most appropriate."

"I believe that students in grade 9-12 would be able to defend their personal ideas. Unfortunately, students in the lower grades may not be able to. They may not have a firm belief of their values."

"What are the central diversity issues in this situation?" This is the first question in case 3 for participants to answer. In comparison the responses to questions of case 3 with the previous two cases, the researcher found that the participants had problems to identify the central diversity issues in this case. Ten participants did not answer this question. Twenty-five participants gave various issues that were partially correct for this case. Therefore, The central diversity issues of case 3 were not clearly identified by the students. Six participants identified the central diversity issues of this case as gender issue. Ten participants did not answer this question, which meant that they could not 
identify the central diversity issues of this case. Twenty-five participants gave various issues that are partially correct for this case.

When it comes to how to handle the situation, the participants provided very good strategies and methods to handle this situation. The researcher thinks that the strategies and methods are appropriate and should be effective under this circumstance.

Twenty-two participants indicated that they would talk to Xeng and Kim separately and privately or ask Xeng to apologize to Kim. The following examples of strategies and methods were provided by the participants:

"I would talk to each of them separately to find out their feelings and viewpoints on the situation. I would discuss how others' feelings are affected by what is said."

"Talk to them each separately. Ask Xeng why he said that. Does he understand how he hurt Kim, etc. Ask Kim if he is ok, reinforce that making fun of Xeng will do no good. Talk to them both together, try to resolve differences."

"In handling this situation, I would do so by taking the boys off to a separate place (hall or corner of the room) and spoke to them about this comment. I would ask Xeng to not say that word in my class again and ask him separately how he knew that Kim was gay. Then I would have Xeng apologize to Kim."

Twelve participants indicated that the class rules should be enforced and Xeng would be punished. The followings are some examples of how would they do to handle the situation:

"Xeng would be punished, if not for his statement, at least for his outburst during class. I would ask Kim how Xeng's comment made him feel \& ask if he would 
like to talk about it."

"This is difficult. I would try to figure out why Xeng blurted that out and if it were not true I would punish Xeng for labeling Kim."

"I would speak generally to the class about reinforcing class rules and that namecalling especially the names like that are not allowed."

In response to the third question of case three, Fifteen participants indicated that they would involve the class in a discussion of this issue under certain conditions such as consulting with parents and administrators first, age factor, and etc. The following are some examples of participants' arguments:

"I would not discuss sexual orientation w/ my students without first consulting with parents \& administrators. Age would be a factor also."

"I would not discuss this with any students without parental permission and permission from the school district. I would explain "gay" is a slang term that is derogatory. The correct terminology is homosexual. I would send a letter home to parents letting them know what conversations had taken place so that they could explain it in a way compatible with their beliefs."

Eight participants argued that they would not get the class involved in discussion on this issue. Here are the examples of the participants' argument:

"I don't think I would allow my class to have discussions like this."

"I would never touch those boundaries. If a cartoon offends a kid just think what a gay person in class would do. You would have parents calling, the principal on your ass, and probably lawyers at your door because you offended someone by saying gay in the class. You have to be very careful what you say in the public 
eye because EVERYONE is offended by EVERYTHING."

"I don't think I would involve the class in a discussion until I knew what was going on. Even then I don't think if I would feel comfortable holding a discussion about this topic." 


\section{CHAPTER V}

\section{CONCLUSIONS AND DISCUSSION}

Chapter five draws final conclusions about students' attitudes, knowledge, and commitment to implementation of multicultural education in a teacher education program from the data analysis of this research. Then it discusses on the effectiveness of the diversity strand in the teacher education program, implications of this study to teacher education curriculum and teaching, and implications and suggestions for further studies.

\section{Conclusions}

\section{Diversity Questionnaire.}

From the results of the T-Test for Diversity Questionnaire we can come to the conclusion that there is not much evidence showing the students' attitude change between Year 3 and Year 4 groups. The reason for this result might be that the one-year difference between the two groups is not sufficient or long enough to see the differences of attitude change. However, the researcher does notice something more in the results of the data analysis. First of all, both Year 3 and Year 4 groups have positive attitudes towards diversity and a better awareness of cultural differences by looking at mean values of the responses to the diversity questionnaire. Secondly, the mean values of 3.59 and 3.21 of the two groups for the first and the third category of statements indicate that the participants of this study do have the knowledge and skills in the respect of lesson planning and instructional design to accommodate the needs of teaching in the diverse setting. So far as the experience of the participants is concerned, the mean value of 3.21 indicates that they do have some exposure to the multicultural communities, multicultural work experiences, and individuals from other cultures. And thirdly, in comparing the 
mean values of 3.18 for Year 3 and of 3.25 for Year 4, one fact is clear that the participants from the Year 4 Group have more exposure to the multicultural communities or multicultural work experiences than Year 3 Group simply because they have one more year in the teacher education program than the Year 3 Group.

This study has important implications for the five-year teacher education program. In order to access what the students have learned from the diversity strand in the teacher education program and to answer the second and the third research questions, the researcher used two instruments -- the "Essay Questions" and "Case Studies" for measurement qualitatively. The results of the measurements further support the results of the Diversity Questionnaire.

\section{Diversity Essay Questions}

The "Essay Questions", which consists of three questions, was given to both year 3 and year 4 groups. The total number of the participants is 149 with 126 females and 23 males respectively. That means female participants are the larger percentage of the population, which is typical of the student population in teacher education programs. Some very interesting thematic domains have emerged from the data analysis of idea units of the "Essay Questions". They reflect what the students have learned from the teacher education diversity strand. To be more specific, the thematic domains include what multicultural/diversity perspectives they have learned, their attitudes and beliefs, their knowledge and experience, their commitment, what they need to know more, and the situations they come across in the field. A few conclusions emerge from the responses of the Essay Questions by both Year 3 and Year 4 groups.

First of all, the participants of this study realize the fact that the 
multicultural/diversity perspectives they have learned from the diversity strand really make a difference in helping them to better understand and respond in a sensitive manner to the needs of students with disadvantaged economically and culturally diverse backgrounds. They mentioned that they have learned from the courses and field experiences about the issues of social economic status and call for treating students equally and stopping prejudice. As mentioned before, the diversity strand has been integrated into the teacher education program for the purpose of adequately preparing students for culturally diverse classrooms. The essay question data shows that the multicultural/diversity perspectives the participants have learned from the courses really help them to understand their students' situations better. The researcher believes that the instructors and administrators in the college have made great efforts to integrate the diversity strand into the five-year teacher education and the efforts are not in vain.

Secondly, this study suggests that the students have developed and formed their positive attitudes toward diversity through the progress of their teacher education program and their field experiences. They believe that diversity awareness and individual needs are very important issues for both students and instructors. They also believe that equity is the heart of diversity in teaching practice. As an instructor teaching in a classroom with students of economically disadvantaged and culturally diverse backgrounds, open-mindedness would be crucial. This study also suggests that the students from both groups have some valuable exposure to diversity and knowledge in their past and field experience. But at the same time, some students from Year 4 Group mention that there are limited multicultural knowledge and experience in the five-year teacher education program. Some students even mention that they have poor preparation 
for diversity. Whether it is true or not, it is a very good warning signal to the program coordinators and instructors that they need to look into the program and see why the students say so, and if they need to reevaluate the program or the design of the diversity strand. To some extent the researcher believes that the diversity strand has been implemented successfully in the teacher education program, but of course, has room for improvements. So far as their commitment is concerned, students from both groups indicate that they are committed to equity and diversity and this is what the instructors expect of them. And most importantly, that is part of the mission of the teacher education program.

Thirdly, this study suggests that the students from both Year 3 and Year 4 groups are eager to know more about other cultures including socioeconomic status, cultural traditions, beliefs and manners. They also want to know more about teaching strategies and methods and need more practice, field experience and content knowledge of their major fields. The students from Year 3 Group indicate that they need to know more about how to have a better understanding of attitudes, students, and diversity issues especially to know more about the approaches to handle certain situations related to equity.

Lastly, this study suggests that students from Year 4 Group have more field experiences than the students from Year 3 Group. Students from Year 4 Group can give at least one situation in their field experience to show that diversity awareness is an important component in our education while 33\% students from Year 3 Group give no response to this question. That means they do not come across such situations in their field experiences. 
The situations they come across in their field experiences for both groups include working with ESL or LEP students, children from lower SES families needing to be helped at home or at school, and situations in which the students do not have experience with or exposure to diversity. The experiences they get from their field placement or volunteer experiences have really helped the students to have better understanding of diversity issues and form positive attitudes towards diversity. Nonetheless, they recognize a need for more exposure and experiences.

\section{Case Studies}

The "Case Studies" is the third instrument used to measure what the students have learned from the teacher education diversity strand. This instrument consists of three cases and questions for each case are designed to test students' ability to identify the theme, problem of the case, and the proper methods and strategies to handle the situations. This instrument was only given to the Year 4 Group. The total number of participants of Year 4 group for the case studies is 60, with 51 females and 9 males. They are in the fourth year of the teacher education program.

The result of the data analysis answered the third research question: "How does the students' awareness of diversity help them to plan and implement multicultural education elements in their teaching?" The researcher draws a few conclusions based on the analysis of the idea units and thematic domains.

First, the students in their fourth year in the program have learned something from the teacher education diversity strand. They do have the knowledge and ability to identify certain diversity issues in real situations. The students' response to the questions of case 1 shows that they can identify the problem correctly and answer the questions 
appropriately. The central diversity issue they have identified for case 1 is "making assumptions or judgment based on appearance and stereotype". They do have the ability to handle the situations, as can be seen from their responses to the second question of case 1--"What would you suggest for Mr. McDonald?" Some participants suggested that he should become more involved with his students. The others suggested that he should never assume anything. These are very good suggestions for Mr. McDonald.

Second, the students' response to the questions of case 2 shows that the participants hold different ideas for each of the questions for case 2. Actually there is a debate over the appropriateness and effectiveness of Ms. Christensen's method of teaching values or challenging students' traditional social and role concepts, especially those based on family and religious values. Some participants indicate that Ms. Christensen's use of literature and movies to teach values are effective, interesting and different and some participants indicate that Ms. Christensen's use of literature and movies to teach values are not effective for certain reasons. Still some others indicate that there would be something they might change or improve if they were in the case situation. However, the researcher found the participants on each side of the issue hold their ideas and try to make their argument strong and persuasive. Some participants state that it is appropriate for teachers to challenge students' traditional social and role concepts, especially those based on family and religious values while others argue that it is not appropriate.

Third, in the case three, the researcher found that the participants have problems identifying the central diversity issues in this case. Some participants do not even answer this question and some participants give various issues that are partially correct for this 
case. Therefore, the central diversity issues of case 3 have not been clearly identified by the students. However, when it comes to how to handle the situation, the participants provided very good strategies and methods. The researcher feels that the strategies and methods are appropriate and should be effective under this circumstance. Like the argument in case 2 the participants also have arguments in case 3 concerning if it is appropriate to get the class involved in the discussion on the diversity issue of this case (sexual orientation and labeling). What conclusions can the researcher make on case 2 and case 3 then? The researcher might come to the conclusion that the students in the teacher education program still need more content knowledge of diversity issues in order to identify diversity issues in different situations. The response of the participants on the diversity issues in case 2 and 3 suggests that the weakness of the teacher education diversity strand is obvious and need to be taken care of in the near future. The weakness of the diversity strand will be discussed in the following section.

\section{$\underline{\text { Discussion }}$}

\section{Teacher Education Diversity Strand}

In reviewing the " Teacher Education Diversity Strand", the document is divided by course into sections which address course objectives, course description, strategies for diversity inclusion, and a list of references specifically focusing on diversity. The document is well written and gives a vivid picture of what you may expect from the diversity strand. The study suggests that the students in the teacher education program benefit from the diversity strand. It is effective to some extent in the respect of general knowledge of diversity issues and strategies and methods to handle certain situations. 
Looking at examples of students' response the researcher singled out for discussion may give some deeper insights on the effectiveness of the diversity strand.

"The topic of diversity just seems to be so glossed over in my classes, and it is presented like it is something that we should already know." (P34/Y4/Q2)

"To be quite honest, I feel I have not had enough (if any) classes that focused on diversity. Of course it has been mentioned in many of my classes, but that has been the extent. I feel like it has been glossed over and as a result it is a bit of a mystery to me. I have not seen any examples of really in-depth teaching. Most of the discussions I have heard concerning diversity have been very superficial." (P34/Y4/Q1)

These examples of the responses suggest that we need to rethink and examine the curriculum of teacher education program in respect to integration of diversity and multicultural issues. They also suggest that diversity strand should be looked as a real and important component of the teacher education program and in-depth teaching would be necessary for further consideration.

\section{Implications for Teacher Education Curriculum and Teaching}

The five-year teacher education program in this college is a well-designed and unique program. The current program is the new teacher education program, which is five years in length and culminate in dual degrees: a bachelors in the subject field or in multidisciplinary studies and a master degree in education. In the list of the Liberal Studies Component, five essential skill areas and six essential knowledge areas are identified and listed. Among these essential skill and knowledge areas, multicultural knowledge or diversity issues are not identified as an essential skill or knowledge area. 
This may be not a big issue since the diversity strand has a separate document or integration plan. The point here is that if multicultural knowledge or diversity awareness is not a required component of the teacher education program, who can guarantee the integration of the diversity strand in all the courses of the program? There is not much research on what the faculty in the teacher education believes about multicultural education and how they actually teach diversity issues in the classroom. But this study suggests that they should examine their teaching practices and develop new awareness about diversity and multicultural issues in the teacher education program. The study also suggests that multicultural knowledge and diversity awareness should be an important component of the teacher education program. Although the study shows that the integration of the diversity strand is effective in some ways, the diversity awareness or multicultural knowledge should be identified as an essential knowledge area for the Liberal Studies Component of Teacher Education, which is the general education core of the teacher education program.

If diversity awareness and multicultural knowledge are identified as essential components in the seventh essential knowledge area, a required 3-credit-hour course on diversity and multicultural knowledge could be added to the curriculum of the teacher education program. If this really happens, the learning experiences of the students in the program will more complete. The problem of "glossing over" can be avoided. The students in the program may be better prepared and have a more comprehensive knowledge base necessary to teach in culturally diverse classroom settings. The study indicates that the multicultural knowledge the students have learned are mostly from the pieces or chunks of the integrated diversity strand in the different courses the students 
have taken and the field placements in the progress of their teacher education program. Therefore, they lack systematic knowledge base of diversity and multicultural issues.

The results of the study emphasize a few issues that impact the implementation of the diversity strand in the teacher education program. Namely, to develop or form positive attitude toward diversity among the students, to acquire a comprehensive knowledge base in order to teach in the culturally diverse classroom settings, to learn the necessary skills to handle the situations in practice, and etc. These issues can serve as areas for discussion or debate among instructors and students. Anyway, the results of this study suggests that faculty in the program might need to look closer at their teaching to see if the diversity strand is effectively implemented and see if they need to have some improvements in the areas of classroom structure and atmosphere, methodology, teaching strategies, and interactions with students. At least the results of this study may attract the attention of faculty and program coordinators who wish to make the diversity strand more effective for the teacher education program and strive to make it a reality.

\section{Implications for Further Study}

This study is a good beginning to evaluate the diversity strand and the teacher education program from the students' perspectives. Further study is needed on the students' attitudes, knowledge and commitment to implementation of multicultural education. This study suggests three potential areas for future research:

1). Use the same instruments to conduct a follow up study for Year 3 group in their 5th year in the program and compare the responses of both studies to see if there is any change during the two year period. This change may be determined by looking at the responses to the three categories of statements of both studies in the diversity 
questionnaire. Conduct another study by using the same instruments to collect data from Year 1 and Year 2 groups and compare the responses with those of the follow up study to see what will happen. Attitude change may be expected to occur during a longer period of time in the program.

2). Examine faculty's attitudes toward diversity strand and how they integrate the diversity issues in their curriculum and teaching. Research in this area will provide us information of what impact faculty's attitudes may have on students' attitudes change or formation, knowledge base development and commitment to implementation of multicultural education.

3). The impact of field experience on students' attitude change. The field experiences may have great impact on students' attitude change. The field placements and volunteer experiences provide the students the environments in which they can have hands on practice of what they have learned from the diversity strand. But different experience may cause the different attitude change either positive or negative. The similar study conducted by Robert A. Wiggins and Eric J. Follo in 1999 concluded: " For some of our students, the experiences we provide in the culturally diverse classrooms may reinforce the negative stereotypes and assumptions we intended to eradicate. Simply being in such a setting does not result in an understanding of, or an appreciation for, the cultural norms of the school or community." (Wiggins \& Follo. 1999) Therefore, what experiences we provide or what else we can do may cause the students to change their attitudes positively? This question need further study.

The results of this study indicate some insights of how the diversity strand works in the teacher education program at this land-grant University. These results may have great 
implications for the whole teacher education field. The researcher is greatly encouraged by the results of this study in the respect of seeing the participants are pretty well prepared to teach in the culturally diverse classrooms with the knowledge and skills learned from the diversity strand. If the diversity strand is fully and better integrated into the courses of teacher education program, the students in the program should graduate with a better knowledge base of diversity issues. If the diversity awareness or multicultural education is identified as one of the essential knowledge areas for the Liberal Studies Component of Teacher Education and if a required course on diversity is added to the teacher education program, the students in the program should graduate with an even better, systematic and comprehensive knowledge base of diversity issues. This will not only benefit the students themselves but also those who are going to be taught by these students in the years to come. 


\section{$\underline{\text { REFFERENCES }}$}

Artiles, A. J. (1995, April). Learning to teach in multicultural contexts: exploring preservice teachers' knowledge change. Paper presented at the annual meeting of the Council for Exceptional Children, Indianapolis, IN.

Banks, J. A. (1990). Citizenship education for pluralistic democratic society. The Social Studies, 81. 210-214.

Banks, J. A. (1991/92). Multicultural education: For freedom's sake. Educational Leadership, 49(4), 32-36.

Banks, J. A. (1992). A curriculum for empowerment, action and change. In K. L. Moodley (Ed.), Beyond multicultural education: International perspectives (pp.154-170). Calgary, Alberta: Detselig Enterprises.

Banks, J. A. (1992, September). Curriculum guidelines for multicultural education. Social Education, 56. 274-294.

Banks, J. A. (1992). Multicultural education historical development dimensions and practice. In L. Darling-Hammond (Eds.), Review of research in education (Vol. 19, pp. 349). Washington, DC: American Educational Research Association.

Banks, J. A. (1993a). Multicultural education: development, dimensions, and challenges. Phi Delta Kappan, 75(1), 22-28.

Banks, J. A. (1993b). Multicultural education: Characteristics and goals. In Banks, J. A. \& Banks, C. A. M. (Eds.), Multicultural education: Issues and perspectives ( $2^{\text {nd }}$ ed.). (pp. 2-26). Boston: Allyn and Bacon. 
Banks, J. A. \& Banks, C. A. M. (Eds.). (1993). Multicultural education: Issues and perspectives ( $2^{\text {nd }}$ ed.). Boston: Allyn and Bacon.

Banks, J. A. ( 1994). Transforming the Mainstream Curriculum. Educational Leadership, 51(8), 4-8.

Baptiste, H. P. (1979). Multicultural education: A synopsis. Washington, DC: University Press of America.

Bennett, C. I. (1990). Comprehensive multicultural education: Theory and practice ( $2^{\text {nd }}$ ed.). Boston: Allyn and Bacon.

Boyle-Baise, M. (1999, Spring). Bleeding boundaries or uncertain center? A historical exploration of multicultural education. Journal of Curriculum and Supervision, 14(3), 191-215

Burnett G. (1994). Varieties of multicultural education: an introduction. ERIC Digest 98 (ERIC Document Reproduction Service No. ED 372 146)

Carmichael, S. \& Hamilton, C. (1967). Black power: the politics of liberation in America. New York: Vintage.

Center for the Renewal of Professional Preparation and Practice. (1994). A new vision for teacher education at West Virginia University. Morgantown, WV.

Chavez, L. (1994, February 21). Demystifying multiculturalism. In Noll J. Wm. (Ed.) Taking sides - Clashing views on controversial educational issues $\left(8^{\text {th }}\right.$ ed., pp. 94-98) Guilford, Connecticut: The Dushkin Publishing Group, Inc.

Chavez, R. C., O'donnell, J., \& Gallegos, R. L. (1994, April 4-8). $\underline{\text { Pre-service students' }}$ perspectives to "dilemmas" in a multicultural education course. Paper presented at the 
annual meeting of the American Educational Research Association, New Orleans, LA.

Chiang, L. H. (1994, October 12-15). A study of the prospective teacher's attitudes toward social diversity. Paper presented at the annual meeting of the Midwestern Educational Research Association, Chicago, IL.

Chisholm, I. M. (1994, Winter). Preparing teachers for multicultural classrooms. Journal of Educational Issues of Language Minority Students, 14, 43-68.

Cortes, C. (1976, January). Need for a goe-cultural perspective in the bicentennial. Educational Leadership, 33, 290-292

Davis, L. E., \& Turner, J. S. (1993, November 9-12). An investigation of the cultural

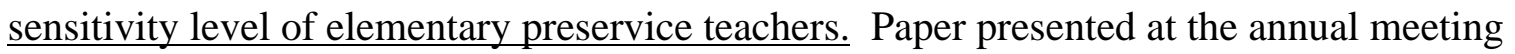
of the Mid-South Educational Research Association, New Orleans, LA.

Frazier, L. (1977). Multicultural facet of education. Journal of Research and Development in Education, 11, 10-16

Garcia, R. L. (1982). Teaching in a pluralistic society: Concept, models, strategies. New York: Harper \& Row.

Gay, G. (1988). Designing relevant curricula for diverse learners. Education and Urban Society, 20, 327-340.

Gay, G. (1990). Achieving educational equality through curriculum desegregation. Phi Delta Kappan, 70, 56-62.

Gollnick, D. M. \& Chinn, P. C. (Eds.). (1990). Multicultural education in a pluralistic society ( $3^{\text {rd }}$ ed.). Columbus, OH: Merrill.

Gonzalez, V. (1993, April 12-16). Using reflective teaching for changing in-service teachers' attitudes and increasing their cognitive-ethical development and academic 
knowledge in multicultural education. Paper presented at the annual meeting of the American Educational Research Association, Atlanta, GA.

Grant, C. (1977a). Education that is multicultural and P/CBTE: Discussions and recommendations for teacher education. In Klassen F. H. \& Gollnick D. M. (Eds.), Pluralism and the American teacher: Issues and case studies (pp.63-80). Washington, DC: Ethnic Heritage Center for Teacher education of the American Association of Colleges for Teacher Education.

Grant, C. A. (1977b). Multicultural education: Commitments, issues, and applications. Washington, DC: Association for Supervision and Curriculum Development.

Grant, C. (1978, September-October). Education that is multicultural -- Isn't that what we mean? Journal of Teacher Education, 29(5), 45-48.

Grant, C. A., \& Tate, W. F. (1995). Multicultural education through the lens of the multicultural education research literature. In Banks J. A. \& Banks C. A. M. (Eds.), Handbook of research on multicultural education (pp.145-166). New York: Macmillan.

Grant, C. A., Boyle-Baise, M., \& Sleeter, C. (1980). The public school and the challenge of ethnic pluralism. New York: Pilgrim Press.

Homan, E. B. \& Person, W. A. (1997, November 12-14). An investigation of the multicultural perceptions of selected secondary social studies student teachers. Paper presented at the annual meeting of the Mid-South Educational Research Association Memphis, TN.

Houston, W. R. (Ed.). (1990). Handbook of research on teacher education. New York: Macmillan.

JoAnn, P.(1994, Summer). Educating teachers for cultural and linguistic diversity: A 
model for all teachers. New York State Association for Bilingual Education Journal, 9 , $1-6$.

McCain-Reid, E. (1994). Seeds of change: A pilot study of senior pre-service teachers' responses to issues of diversity in one university course. (ERIC Document Reproduction Service No. ED 376 227)

Min Liu, David J. Ayersman \& W. Michael Reed (1995), Perceptions of a Hypermedia Environment. Computers in Human Behavior, 11(3-4), 411-428.

Moore, T. L., \& Reeves-Kazelskis, C. (1992, November 10-13), Effects of formal instruction on preservice teachers' beliefs about multicultural education. Paper presented at the annual meeting of the Mid-South Educational Research Association, Knoxville, TN.

Nieto, S. (1992). Affirming diversity: The sociopolitical context of multicultural education. New York: Longman.

Parekh, B. (1986). The concept of multicultural education. In Modgil, S., Verma, G. K., Mallick, K., \& Modgil, C. (Eds.), Multicultural education: The interminable debate (pp. 19-31). London: Falmer Press.

Redman, G. L. (1999). A Casebook for Exploring Diversity in K - 12 Classrooms. New Jersey: Prentice-Hall, Inc.

Reed, D. F. (1993, Fall). Multicultural education for preservice students. Action in Teacher Education, 15(3), 27-34.

Regan, S. D. (1983, March 20-23). Mandated multicultural education: boon or boondoggle. Paper presented at the annual convention of the American Personnel and Guidance Association, Washington, DC. 
Schlesinger, A. M. Jr. (1991, Winter). The disuniting of America: what we all stand to lose if multicultural education takes the wrong approach....: $\underline{\text { American Educator: The }}$ Professional Journal of the American Federation of Teachers, 15(3), 14,21-33.

Sizemore, B. A. (1981). The politics of multicultural education. Urban Education, 5, 4-11.

Sleeter, C. \& Grant, C. (1987, November). An analysis of multicultural education in the United States. Harvard Educational Review, 57, 421-444.

Sleeter, C. E. (Ed.). (1991). Empowerment through multicultural education. Albany: State University of New York Press.

Sleeter, C. E. \& Grant, C. (1994). Making choices for multicultural education: five approaches to race, class, and gender. ( $2^{\text {nd }}$ ed.). New York: Merrill.

Sobol, T. (1990). Understanding diversity. Education Leadership, 48(3), 27-30.

Sultana, Q. (1994, November 8-11), Evaluation of multicultural education's understanding and knowledge in freshman level preservice teachers. Paper presented at the annual meeting of the Mid-South Educational Research Association, Nashville, TN.,

Sultana, Q. (1993, November 10-12). Evaluation of multicultural education in a preservice teacher education program. Paper presented at the annual meeting of the MidSouth Educational Research Association, New Orleans, LA.

Suzuki, B. H. (1979). Multicultural education: What's it all about. Integrated Education, 17(1-2), 43-50.

Suzuki, B. H. (1984). Curriculum transformation for multicultural education. Education and Urban Society, 16, 294-322.

Washburn, D. E. (1994, Winter). Let's take a hard look at multicultural education. 
Multicultural Education, 2(2), 20-23.

Webb-Johnson, G., Artiles, A. J., Trent, S. C., Jackson, C. W. \& Velox, A.(1998 January/February). The status of research on multicultural education in teacher education and special education. Remedial and Special Education,19(1), 7-15.

Wergin, J. F. (1989, November 2-5). Assessing student attitudes towards cultural diversity. Paper presented at the annual meeting of the Association for the Study of Higher Education, Atlanta, GA.

Wiggins. R. A. \& Follo. E. J., (1999, March-April). Development of knowledge, attitudes, and commitment to teach diverse student populations. Journal of Teacher Education, 50(2), 94-105.

Winitzky, N. \& Barlow, L. (1998, April 13-17). Changing teacher candidates' beliefs about diversity. Paper presented at the annual meeting of the American Educational Research Association, San Diego, CA. 


\section{APPENDIX A}

\section{DIVERSITY QUESTIONNAIRE}

Please respond to the following statements as best you can based on your experiences up to this point. We will ask you to respond to the same statements again at the end of the semester. Please be assured that we are looking only for trends in student growth and development as a means to assess our teacher education program. This is not an assessment of individual students. All responses will be kept confidential. Please do not place you name on the question paper or the scantron sheet.

Code - Please choose a four-digit code that you will be sure to remember. Fill in those numbers under A, B, C, and D of the IDENTIFICATION NUMBER space in the lowerleft corner of the answer sheet. You will need to indicate this code again on the end of semester questionnaire. The code number will be used only to match pre- and postsemester questionnaires

1. Current Course No.

2. Current Field Placement

3. No.of semesters in the Program

Please respond to statements 4 - 38 using the scale below

Strongly Disagree Neutral Strongly Agree

4. $\quad \begin{array}{llllll}1 & 2 & 3 & 4 & 5 & \text { I know what multicultural education means. }\end{array}$

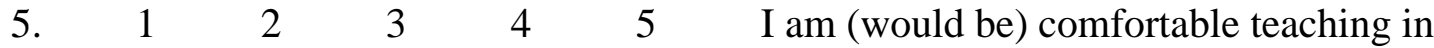
culturally diverse classrooms with students who share different value systems.

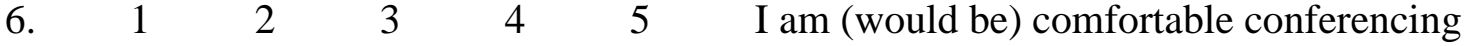
with parents of diverse cultures.

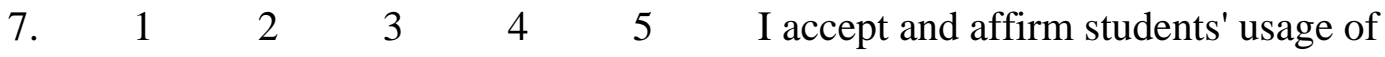
nonstandard English.

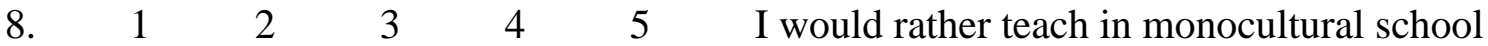
settings.

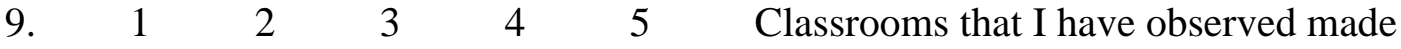
mention of the contributions of people from various racial cultural and economic groups. 


\section{Diversity Questionnaire P. 2}

Strongly Disagree Neutral Strongly Agree

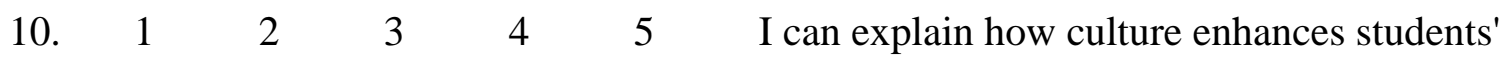
learning of academic content.

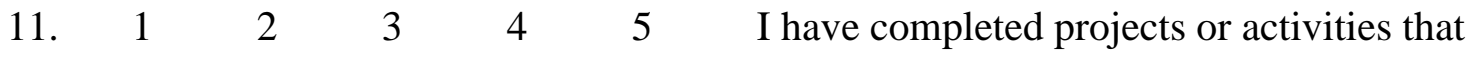
caused me to explore the relationship between instructional strategies and student self-esteem.

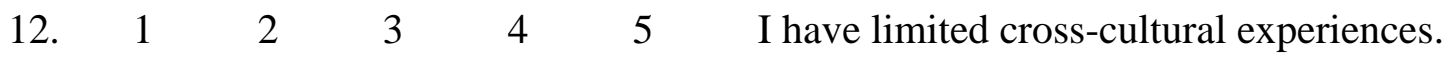

13. $1 \quad 1 \quad 2 \quad \begin{array}{lllll} & 2 & 4 & 5 & \text { I believe that some minority groups, such as }\end{array}$ Blacks and Hispanics, may not be as capable of learning as other minority groups, such as Asians.

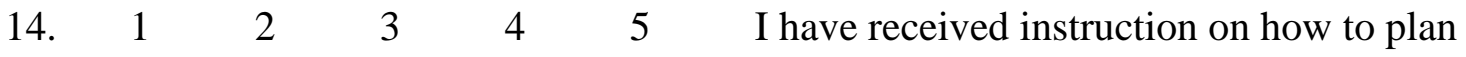
and implement multicultural lessons.

15. $1 \quad 1 \quad 2 \quad 3 \quad 3 \quad 4 \quad 5 \quad$ I have examined school curriculum materials, including textbooks, for evidence of bias.

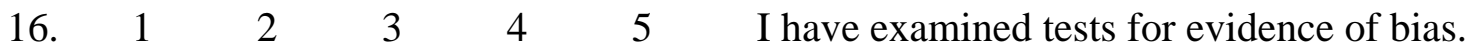

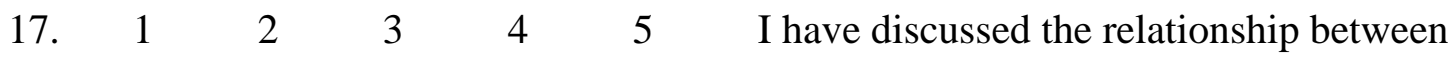
hidden curricula and unintended cultural bias.

18. $1 \quad 2 \quad 2 \quad 3 \quad 4 \quad 5 \quad$ I am able to describe the relationship between local communities and schools in all economic and social areas, especially urban public schools where students are frequently disadvantaged.

19. $1 \quad 1 \quad 2 \quad \begin{array}{lllll} & 2 & 4 & 5 & \text { I prefer teaching students who share my }\end{array}$ social class and cultural background.

20. $1 \quad 1 \quad 2 \quad 3 \quad 3 \quad 4 \quad 5 \quad$ I have completed projects or activities that included aspects of multicultural education

21. $1 \quad 1 \quad 2 \quad 3 \quad 3 \quad 4 \quad 5 \quad$ I believe that limited-English-proficiency (LEP) students need lower-level work. 


\section{Diversity Questionnaire P. 3}

Strongly Disagree Neutral Strongly Agree

22. $11 \quad 2 \quad 3 \quad 3 \quad 4 \quad 5 \quad$ I'm unsure about the cultural qualities of social groups other than my own.

23. $11 \quad 2 \quad 3 \quad 3 \quad 4 \quad 5 \quad 5$ I'm unsure how biases and stereotypes that I might have for other cultural groups could unintentionally influence my classroom instruction.

24. $11 \quad 2 \quad 3 \quad 3 \quad 4 \quad 4 \quad 5 \quad$ I have seen school classroom environments with instruction that appeared to be multicultural.

25. $12 \quad 2 \quad 3 \quad 4 \quad 5 \quad$ I can identify subtle forms of racism, including unintended cultural bias, that might influence my own teaching.

26. $1 \quad 1 \quad 2 \quad 3 \quad 3 \quad 4 \quad 5 \quad$ I have a limited understanding of how sociocultural and/or cognitive factors related to student diversity could influence my personal and academic relationship with students.

27. $1 \quad 1 \quad 2 \quad 3 \quad 3 \quad 4 \quad 5 \quad 5 \quad$ I am (would be) able to tailor instruction to the needs of all my students.

28. $1 \quad 1 \quad 2 \quad 3 \quad 3 \quad 4 \quad 5 \quad$ I know how to design and implement lessons that are instructionally appropriate and academically challenging for all students.

29. $1 \quad 1 \quad 2 \quad 3 \quad 3 \quad 4 \quad 5 \quad$ I can develop strategies that engage all students in instruction and that help them express themselves confidently at school.

30. $1 \quad 1 \quad 2 \quad 3 \quad 3 \quad 4 \quad 5 \quad$ I have participated in discussions that have focused on how to adapt different teaching strategies to the various learning styles of my students.

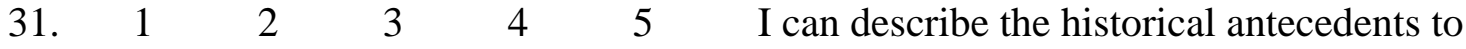
the marginalization of Black and Hispanic students at school. 


\section{Diversity Questionnaire P. 4}

Strongly Disagree Neutral Strongly Agree

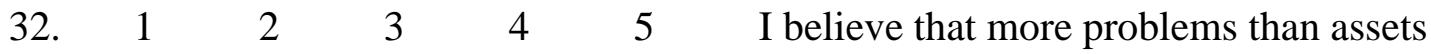
surround cultural diversity at school.

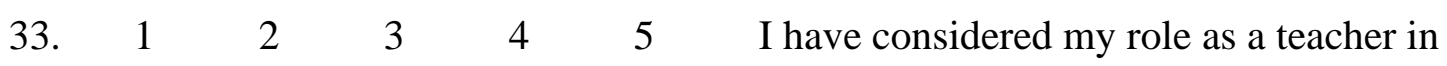
school-community relations

34. $1 \quad 1 \quad 2 \quad 3 \quad \begin{array}{llll} & 2 & 3 & \text { I have a limited understanding of the }\end{array}$ complex relationship among society, schools, and ethnicity.

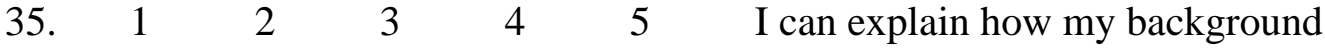
experiences influence the values and beliefs I hold for making classroom decisions about curriculum and instruction.

I am comfortable raising questions about multicultural issues

36. $1 \quad 1 \quad 2 \quad 3 \quad 34 \quad 5 \quad$ (a) in groups of peers

37. $1 \quad 1 \quad 2 \quad 3 \quad \begin{array}{llll}\text { 3 } & 2 & 3 & \text { (b) in my teaching }\end{array}$

$\begin{array}{lllllll}\text { 38. } & 1 & 2 & 3 & 4 & 5 & \text { (c) in university or other formal educational }\end{array}$ settings.

39. Have you taken classes that heightened your awareness of multicultural issues?

no __yes Which Classes? 


\section{Diversity Questionnaire P. 5}

40. Can you identify any other experiences that heightened your awareness or change your views on multicultural issues?

Thank you for your participation

\section{IDENTIFICATION NUMBER:}
A $B \quad C \quad D$ 


\section{APPENDIX B \\ CULTURAL DIVERSITY ESSAY QUESTIONS}

Please respond to the following statements and questions as best you can based on your knowledge and experiences up to this point.

\section{General Information:}

1. Sex

2. Age

3. Current Course No.

4. No. of semesters in the program

5. List Field Placements (if applicable) you've had in your teacher preparation program

\section{IDENTIFICATION NUMBER:}

\section{A $\quad$ B $\quad$ C $\quad$ D}

\section{Questions:}

1. Please describe how multicultural/diversity perspectives you have learned by this time really make a difference in helping you to better understand and respond in a sensitive manner to the needs of students with economically disadvantaged and culturally diverse backgrounds? Your attitudes? Your knowledge? Your skills? Your commitment?

2. With respect to multicultural/diversity issues, what do you think you need to know more about in order to teach your subject area effectively to students from diverse backgrounds?

3. From your experiences in the field, describe 3 situations you came across that make you believe that diversity awareness is an important component in our education: 


\section{APPENDIX C}

\section{CASE STUDIES}

Please respond to the following reflection questions in each case as best you can based on your knowledge and experiences up to this point.

\section{General Information:}

1. Sex

2. Age

3. Current Course No.

4. No. of semesters in the program

5. List Field Placements (if applicable) you've had in your teacher preparation program

\section{IDENTIFICATION NUMBER:}

\section{A $\quad$ B $\quad$ C $\quad$ D}

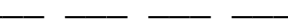

II. Cases and Questions:

\section{Case 1}

\section{A New Student and a Lesson in Geography}

As are most teachers, Mr. McDonald was a dedicated and creative teacher who cared about his students. Teaching was his passion.

Nearly all the students in Mr. McDonald's class lived in the economically deprived neighborhood in which the school was located. Only about 15 percent of the student body were of middle-class means.

It was the sixth week of school when Peter, an African American transfer student from Chicago, entered his class. Peter was dressed like the other students, with a T-shirt and worn blue jeans. Mr. McDonald welcomed Peter into the class and gave him the usual materials, a text, handouts related to the current unit, and a set of free lunch tickets for the 
remainder of the week.

“Any questions?” asked Mr. McDonald.

"Yeah," Peter said. "What am I supposed to do with these tickets?"

"Just give them to the woman at the cash register in the lunchroom," replied Mr.

McDonald. He then began his lesson on European history.

Later in the hour, when he was well into his lesson, Mr. McDonald asked, "Can anyone tell me if one could get to Europe via the North Sea?" Peter quickly shot his hand into the air with confidence. "Yes. Actually I've crossed the North Sea by boat with my family"

Doubting that Peter had ever made such a trip, Mr. McDonald replied, "You're right, Peter; it is possible to reach Europe by the North Sea." As the hour was coming to an end, Mr. McDonald reminded students of the homework for the next day. Just as the dismissal bell rang, he finished giving the assignments.

On the way out, Robert, a slight boy, stopped by Mr. McDonald, who was standing at the door. In the past few days the boy had become a bit more "clingy." He also seemed to have more difficulty sitting stillhimself. "See you tomorrow, Robert," said Mr. McDonald. Robert smiled and disappeared in a sea of faces.

On his way out of the room, Peter asked Mr. McDonald where he should go to get a bus pass. Mr. McDonald informed Peter that he would not need one-that all the kids walked home. Peter glanced quizzically at his new teacher and then was swallowed by the stream of students.

The next morning when Mr. McDonald made his usual stop in the principal's office to get his announcements and messages, the school secretary reminded him to have Peter pick 
up his bus pass. Mr. McDonald admitted that he had told Peter to walk home the day before.

"Five miles!?" asked the secretary "You know he lives in Roseville [a middle-class suburb],don't you?"

Mr. McDonald admitted that he had not known that Peter's family lived in the neighboring middle-class community. “That explains Peter's puzzled look when I handed

him the free lunch tickets," he thought. Mr. McDonald wondered what he would say to Peter later that day in class.

\section{Questions for Reflection}

1. What do you see as the problems in this case?

2. What would you suggest for Mr. McDonald? 
Case 2

\section{Developing Skills of Critical Analysis:}

\section{Exposing the Myths of Films and Fairy Tales*}

Ms. Christensen wanted her students to develop the tools necessary to critique every idea in terms of the degree to which it contributes to or distracts from the building of a just society. To this end, each year her class embarked on a journey of exploration of cartoons, children's movies, and stories.

This year she planned to begin with Ariel Dorfman's The Empire's Old Clothes: What the Lone Ranger. Babai; and Other Innocent Heroes Do to Our Minds, in which the author claims that both popular literature and children's literature perpetuate existing power structures and deny the possibility of greater equality.

Next, the class would critique cartoons and children's movies, including those with stars such as Bugs Bunny, Daffy Duck, Heckle and Jeckle, The Little Mermaid, Sleeping Beauty, Cinderella, Snow White, and Popeye, as the first step in dismantling old values and constructing more just ones. The class would identify roles of people of color, as well as men's and women's roles in the films. They would look at the power relationships among the characters; listen for loaded words, such as "backward," "primitive," and "lazy"; and consider the effect of the story on the self-image of members of a diverse audience.

The final leg of the journey would involve students in sharing their critiques with audiences beyond the classroom. Such a step would suggest to students that their efforts were of larger import and indeed might lead to changes in their school, community, or 
state. Some students wrote a pamphlet to distribute to parents serving on school advisory boards, while others watched Saturday morning cartoons and wrote a report card for each ("Popeye" received an "F" because of its portrayal of ethnic groups as stupid and Americans as superior, and "Teenage Mutant Ninja Turtles" received a "D" because of its focus on using violence to solve problems).

Ms. Christensen noted that each year most students looked deeper into the issues and understood, for example, the master/servant relationship or how the images affected the dreams and goals of viewers or readers. A few, however, shrugged their shoulders and suggested that being rich or poor is OK, or that kids just read or view fairy tales as fun and do not really internalize the values portrayed. Ms. Christensen recalled occasional statements from students such as, "Just because girls see Tinkerbelle or Cinderella with tiny waists doesn't mean they'll want one." She wondered: "How can I determine how many of my students hold such beliefs and how firmly they hold them? How can I assess the degree to which my students are developing the knowledge, skills, and dispositions for thinking critically? What about performance and authentic assessment or portfolios?"

\section{Questions for Reflection}

1. What did you find effective about Ms. Christensen's use of literature and movies to teach values? What might you change?

2. Is it appropriate for teachers to challenge students' traditional social and role concepts, especially those based on family and religious values? If so, at what ages and under what conditions? If not so, give your reasons for saying that. 


\section{Case 3}

\section{Not in My Group-He's Gay}

Ms. Collins was a firm believer in education that is multicultural and has the potential to lead to social reform. She organized her curriculum around issues of race, gender, class, disability, language, and affectional orientation. She used the lives of students in her classes as the starting point for addressing such issues.

On this day Ms. Collins's students were busily engaged in heterogeneous small group discussions about their family heritage projects. She had asked them to share the information about their ethnic heritage obtained from their parents or guardians the night before. Ms. Collins hoped that not only would the small group discussions give her pupils opportunities to express themselves, but they might also help identify differences and similarities among classmates. Certainly, she thought, the discussions would help them be more thoughtful about what else they would need to find out to make their projects more complete.

As she moved to the small group of students in the rear of the room, Xeng, a Hmong student new to the class, said to her as he pointed to a classmate named Kim: "Keep him away from me. He's gay!" The other group members covered their mouths and laughed.

Ms. Collins was caught by surprise. Consistent enforcement of class rules established at the beginning of the school year had prevented the use of such labels in her class until today. She noticed that Kim appeared embarrassed by Xeng's accusation.

"Do you know what 'gay' means?" she asked, in an effort to determine if Xeng was just repeating something he had heard an adult say, without knowing what it meant. 
"Yes," replied Xeng. "It's when one man has sex with another man.

Ms. Collins was baffled. She thought to herself, "Should I ask if Xeng is sure, or how he knows that Kim is gay? Should I ask Xeng if he is angry with Kim, and, if so, why? Should I reprimand Xeng for making his judgment public? How should I respond to Kim?"

\section{Questions for Reflection}

1. What are the central diversity issues in this situation?

2. Write several sentences illustrating how you would handle the situation.

3. Under what conditions, if any, would you involve the class in a discussion of this issue? What actual opening statements/questions would you use to introduce such a discussion? 